TAO, Vol. 16, No. 5, 959-987, December 2005

\title{
Cloud Parameterizations in SUNYA Regional Climate Model for the East Asia Summer Monsoon Simulations
}

\author{
Chao-Tzuen Cheng ${ }^{1, *}$ and Wei-Chyung Wang ${ }^{1}$
}

(Manuscript received 15 January 2004, in final form 8 July 2005)

\begin{abstract}
East Asia summer monsoon (EASM) simulations are conducted to evaluate three schemes which determine cloud properties used in the radiation calculation of the State University of New York at Albany (SUNYA) regional climate model (RCM). Scheme-I uses diagnostic cloud cover and cloud water while Scheme-II uses prognostic cloud water along with overcast sky; both schemes are commonly employed in RCMs. In Scheme-III, cloud cover is determined by diagnostic formula, but the cloud water is calculated by the weighted means of its diagnosed and prognosed values. Therefore, Scheme-III considers the subgrid-scale clouds as Scheme-I and maintains consistent cloud properties in radiation calculation and microphysical processes as Scheme-II. Cloud radiative forcing (CRF) which provides a quantification of the cloud-radiation-climate interaction is adopted to compare the three schemes in simulating the 1991 EASM, characterized by large amounts of cloud and persistent rainfall over Yangtze-Huai River valley.

With these three cloud schemes, the SUNYA RCM is capable of simulating the intra-seasonal variations of observed cloud cover and longwave CRF. The transition of shortwave CRF is not properly simulated due to the constantly presented low-level clouds. Mostly the magnitude of CRF is overestimated by $13-22 \mathrm{~W} \mathrm{~m}^{-2}$ for shortwave CRF and by $12-16 \mathrm{~W} \mathrm{~m}^{-2}$ for longwave CRF. It is also found that the surface temperature biases are highly correlated (with correlation coefficient greater than 0.8 ) to the shortwave CRF biases. Therefore, Scheme-III resulting in less low-level cloud water and the least shortwave CRF biases simulates surface temperatures in better agreement with observations. Analyses of surface energy balance components indicate that the CRF changes dominate the surface temperature
\end{abstract}

\footnotetext{
${ }^{1}$ Atmospheric Sciences Research Center, State University of New York, Albany, USA

* Corresponding author address: Dr. Chao-Tzuen Cheng, Atmospheric Sciences Research Center, State University of New York, Albany, USA; E-mail: ctcheng@climate.cestm.albany.edu
} 


\begin{abstract}
responses and the consequent surface latent heat and sensible heat flux feedbacks significantly offset them. Finally, comparisons of the diurnal variations of simulated cloud water among the three schemes show that SchemeIII provides consistency between cloud microphysics and radiation.
\end{abstract}

\author{
(Key Words: Cloud parameterization, East Asia summer monsoon, \\ Regional Climate Model)
}

\title{
1. INTRODUCTION
}

Cloud parameterization determining the heating/cooling of the atmosphere through latent heat release and cloud radiative forcing (CRF) is an important element in climate simulations. The cloud formation/dissipation depends on cloud microphysics processes in response to atmospheric thermodynamic states while the CRF depends on number density, size, optical properties, temperature, and vertical association of clouds. Apparently, cloud properties in these two aspects should be consistently treated to simulate the cloud-radiation-climate interactions. However, cloud parameterization development is a challenging task (Randall et al. 2003) due to the complexity of cloud processes and their interplay (IPCC 2001).

In most climate models, cloud properties are either predicted by prognostic equations (Tiedtke 1993; Del Genio et al. 1996; Lohmann and Roeckner 1996; Fowler et al. 1996; Rasch and Kristjánsson 1998) or diagnosed by empirical formulas (Slingo and Slingo 1991; Liang and Wang 1995; Hack 1998). Because the cloud microphysical processes in prognostic equations directly respond to the thermodynamic state, using prognostic clouds in all physical processes is an ideal approach to treat cloud-climate interaction. However, prognostic clouds usually cannot explicitly resolve subgrid-scale clouds due to the coarse resolutions of climate models unless the fractional cloudiness is considered in cloud microphysics. Neglecting subgridscale clouds will lead to an underestimation of cloud-radiative effects for grids which do not produce prognostic clouds for their subsaturated mean humidity.

On the other hand, diagnostic clouds can represent both grid- and subgrid-scale clouds but their interaction with climate is indirect, primarily through the changes in relative humidity and vertical motion, and limited by empirical parameters. The inappropriate cloud representation certainly could yield incorrect interactions between thermodynamics and circulation. For example, large biases of radiative fluxes as well as the strength of monsoon circulations are simulated when prescribed cloud properties are used in the Asian summer monsoon simulation of Sharma et al. (1998). Besides the limited interaction, the variation of grid mean diagnostic cloud water may be different from that of prognostic cloud water, resulting in inconsistence between cloud microphysics and cloud radiation calculation, and thus inappropriate cloudradiation-climate interactions.

Although cloud cover (CC) has been introduced in prognostic equations of clouds (Tiedtke 1993; Del Genio et al. 1996; Lohmann and Roeckner 1996; Rasch and Kristjánsson 1998) to represent subgrid-scale clouds, many climate models still do not consider subgrid-scale clouds, especially for many regional climate models (Giorgi 1999; Leung et al. 1999; Wang et al. 
2000). To minimize the aforementioned drawbacks of merely using diagnostic and prognostic clouds alone, a cloud hybrid scheme is proposed and applied in a regional climate model (RCM) with horizontal resolution of $60 \mathrm{~km}$. Thus, both subgrid- and grid-scale clouds can be represented without remarkably modifying the microphysics of prognostic clouds.

The main objective of this study is to use the State University of New York at Albany (SUNYA) RCM, which has been demonstrated to be able to simulate the meso-scale characteristics of the 1991 East Asian summer monsoon (EASM; Leung et al. 1999, Wang et al. 2000, and Gong and Wang 2000), to evaluate different cloud schemes in simulating the cloud cover and water and to examine the consistency of these parameters in physical processes. The cloud and rain belts associated with the semi-stationary Mei-Yu fronts are the most important features of the EASM, extending thousands of kilometers, elongating from Japan to the southwest China (Tao and Chen 1987). The long lasting and extended clouds greatly reduce surface incoming solar radiative and heat fluxes as well as atmospheric latent heat release and radiative heating, which play key roles in triggering and maintaining monsoon circulations.

To determine the cloud properties used in radiation calculation, the following three cloud schemes are considered: Scheme-I uses diagnostic cloud water and diagnostic cloud covers to represent the diagnostic clouds; Scheme-II uses prognostic cloud water along with overcast sky (i.e., $100 \%$ cloud cover) to represent the prognostic clouds; and Scheme-III averages diagnostic and prognostic cloud water along with diagnostic cloud covers to represent the hybrid clouds. The hybrid scheme considers both the grid-scale and subgrid-scale clouds and has direct interaction and coupling between radiation and thermodynamics. We evaluate these schemes by analyzing the CRF, surface temperatures, surface energy balance, and diurnal variations of the low-level clouds of simulations. Three experiments are conducted, designated as EX_diag, EX_prog, and EX_hyb respectively, for the three cloud schemes-I, -II, and -III. Thereafter, clouds are referred to as diagnostic clouds, prognostic clouds, and hybrid clouds when they are decided by Scheme-I, Scheme-II, and Scheme-III, respectively. The treatment of the three major cloud parameters is summarized in Table 1. The results of EX_diag are used as references when comparisons among simulated data are made otherwise observations are given specific reference when discussing model biases. Details of these three cloud schemes and the relevant observation data are introduced in Section 2. Observed cloud features, model performance, simulation biases are presented in Section 3. The responses of land-surface energy budget to different cloud schemes, and the features of diurnal cycles of cloud fields are discussed in Section 4. Section 5 gives conclusions and discussion.

\section{APPROACH}

\subsection{The Cloud Schemes}

The radiation package of National Center for Atmospheric Research Climate Community Model (NCAR CCM3) version 3 (Kiehl et al. 1998), which considers three major cloud parameters (cloud water path, cloud fraction, and cloud droplet effective radius) to account for clouds in radiation calculations, is used in this study. Based on these three cloud parameters, 
Table 1. Cloud property configurations adopted in the three experiments with different cloud schemes for radiation calculation. Cloud covers are diagnosed by the scheme of Liang and Wang (1995). Hybrid cloud water is calculated by Eq. (4) and (5). Effective radius determined by Eqs. (1) to (3) depends on cloud water and prescribed cloud droplet number density while the one of Kiehl (1994a) depends on the temperature and pressure.

\begin{tabular}{cccc}
\hline \hline Experiment & Cloud Cover & Cloud Water & Effective Radius \\
\hline EX_diag (Scheme-I) & Diagnostic & Diagnostic & Kiehl (1994a) \\
EX_prog (Scheme-II) & $99.9 \%$ or 0\% & Prognostic & Eq. (1) to (3) \\
EX_hyb (Scheme-III) & Diagnostic & Hybrid & Eq. (1) to (3) \\
\hline
\end{tabular}

three cloud schemes (Scheme-I, -II, and -III) are formulated as follows. Scheme-I uses empirical formulas to calculate cloud water path, cloud cover, and droplet effective radius. The incloud cloud water path $\left(C W P_{\text {diag }}\right)$ is decided by the diagnostic scheme of Hack (1998), which depends on the values of precipitable water and a specified scale height. The maximum value of the in-cloud cloud water content of about $200 \mathrm{mg} \mathrm{kg}^{-1}$ occurs in the fourth lowest layer because no cloud is considered in the lowest three layers in SUNYA-RCM for radiation calculation. The liquid and ice cloud droplet effective radius, $\left(r_{e l}\right.$ and $\left.r_{e i}\right)$ are parameterized as functions of temperature, pressure, and land-sea distribution, as in CCM3 (Kiehl 1994a; Kiehl et al. 1998). For the cloud cover, we use the diagnostic scheme of Liang and Wang (1995), which is modified from Slingo and Slingo (1991): the cloud fraction of convective clouds depends on convective rainfall while the stratiform cloud fraction is decided by relative humidity first and then adjusted by the large-scale subsidence. Both grid-scale and subgrid-scale clouds can be represented by Scheme-I, depending on whether the grid is saturated or not. Through the changes in relative humidity, vertical motion, and convective rainfall, cloudradiation interaction is performed but with limited variability due to the limited changes in incloud cloud water and cloud droplet effect radius. However, the diagnostic approach like Scheme-I is simple and widely used in many climate models.

Scheme-II uses prognostic cloud water (Dudhia 1989) along with a cloud cover of either overcast or clear-sky, depending on whether the cloud water is greater than $0.1 \mathrm{gm}^{-2}$ or not, in radiation calculation. The prognostic cloud water path $\left(C W P_{\text {prog }}\right)$ is calculated as $C W P_{\text {prog }}=C W C_{\text {prog }} \cdot \Delta z$, where $C W C_{\text {prog }}$ indicates the predicted cloud water content and $\Delta z$ the thickness of grid box. The liquid cloud droplet effective radius is parameterized in terms of cloud water content and 
droplet number concentration N (Martin et al. 1994; Gultepe et al. 1996; Lohmann et al. 1999; Reid et al. 1999; Iacobellies and Somerville 2000):

$$
\begin{aligned}
& r_{e l}=\left(C W C_{p r o g} \cdot \frac{3}{4 \pi \rho_{l} k_{m} N}\right)^{1 / 3}, \\
& N=N_{0} \cdot \operatorname{EXP}\left(-\frac{h}{H}\right),
\end{aligned}
$$

where $\rho_{l}$ is the liquid water density. $k_{m}=0.8$ for the maritime clouds and $k_{m}=0.67$ for the continental clouds are required factors to estimate the effective radius from the mean volume radius (Martin et al. 1994). With the scale height of $\mathrm{H}=3.57 \mathrm{~km}$ (Pruppacher and Klett 1997), the liquid cloud droplet number concentration decreases exponentially as the height of cloud, h, increases. Based on the warm stratocumulus cloud measurements of Martin et al. (1994), the mean droplet concentration for each individual measurement ranges $35-200 \mathrm{~cm}^{-3}$ over ocean, and $100-500 \mathrm{~cm}^{-3}$ over land. In this study, $N_{0}=100$ and $300 \mathrm{~cm}^{-3}$ is respectively chosen to calculate the effective radiuses of liquid cloud drops over ocean and land. In addition, the following empirical formula of Lohmann et al. (1999) is used to calculate the effective radiuses of ice cloud drops.

$$
r_{e i}=83.3 \times\left(1000 \cdot C W C_{\text {prog }}\right)^{0.216},
$$

where the unit of $C W C_{\text {prog }}$ is $\mathrm{kg} \mathrm{m}^{-3}$ and the unit of $r_{e i}$ is $\mu \mathrm{m}$.

The differences between diagnostic and prognostic clouds are identified in Fig. 1 which shows the seasonal (from May to July 1991) and zonal mean (from $105^{\circ}-120^{\circ} \mathrm{E}$ ) vertical profiles of clouds. In Ex_diag, the diagnostic cloud water contents (Fig.1a) are much smaller than the predicted ones (Fig. 1b). The effective cloud covers, a major cloud parameter defined as cloud cover times cloud emissivity for longwave radiation calculation, of Ex_diag and Ex_prog are respectively shown in Figs. 1c, d. Apparently, the vertical distributions of effective cloud covers are very different, with more high-level clouds and less middle-level clouds appearing in EX_prog, resulting in different impacts on radiative fluxes.

Scheme-III calculates the cloud water for radiation calculation by taking the weighted mean of the diagnostic and prognostic cloud water paths. The cloud water path of the hybrid cloud $\left(C W P_{h y b}\right)$ is shown as follows:

$$
\begin{aligned}
& C W P_{\text {hyb }}=C W P_{\text {prog }} \times f+C W P_{\text {diag }} \times(1-f), \\
& f=\operatorname{MIN}\left\{1 ., \operatorname{MAX}\left[0 .,\left(\frac{R H-R H_{c}}{100 \%-R H_{c}}\right)^{2}\right]\right\},
\end{aligned}
$$




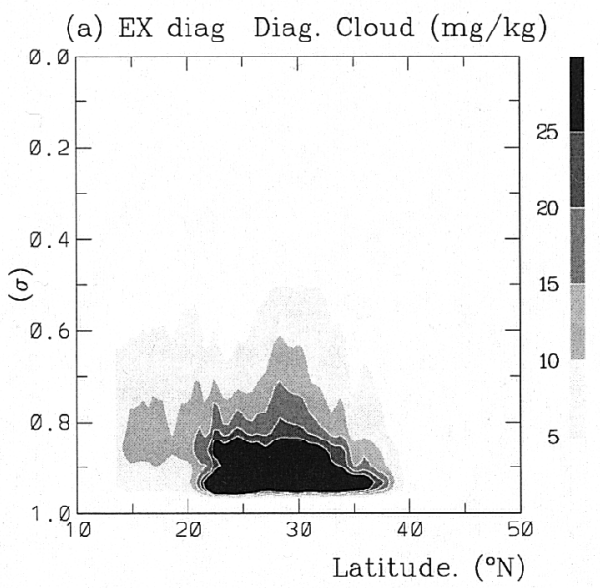

(b) EX diag Prog. Cloud (mg/kg)

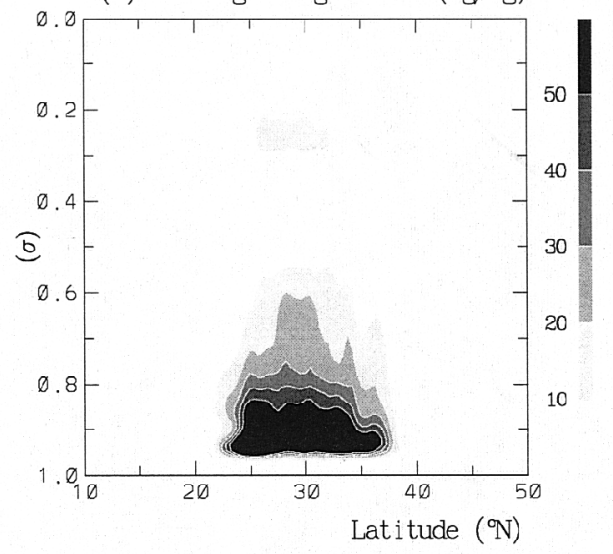

(c) EX diag EffCld (\%)

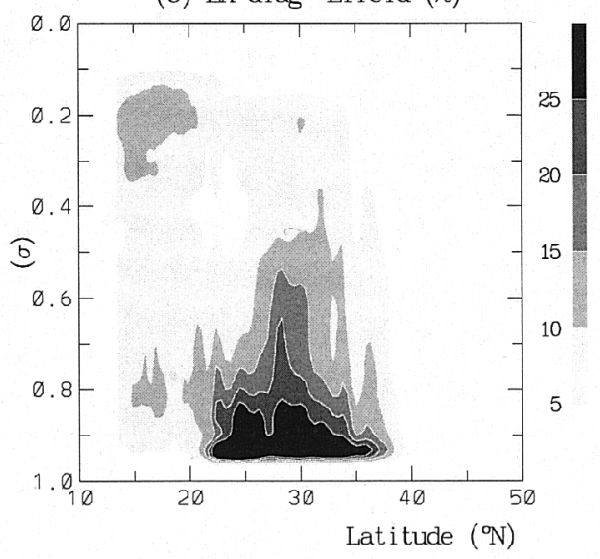

(d) EX prog EffCld (\%)

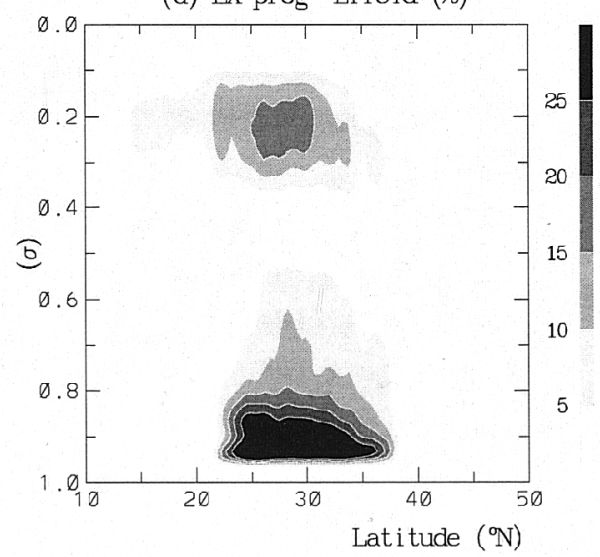

Fig. 1. Height-latitude distributions of the seasonal and zonal mean (a) diagnostic cloud water mixing ratios, (b) prognostic cloud water mixing ratios, and (c) effective cloud fractions of diagnostic clouds; and that of (d) the effective cloud fractions of prognostic clouds.

where the critical relative humidity, $R H_{c}$, is set as $95 \%$. The weighting function of (5) is based on the idea that clouds are completely represented by grid-scale prognostic clouds when relative humidity is near saturation, and are totally represented by subgrid-scale diagnostic clouds when the relative humidity is smaller than a specified critical value $\left(R H_{c}\right)$. Diagnostic cloud covers are used in Scheme-III irrespective of the grid boxes being saturated or subsaturated as it is overcast when $R H=100 \%$ and there is no subsidence. Treating prognostic cloud water as the in-cloud quantity together with a diagnostic cloud cover which takes into account the effects of large scale subsidence can result in more realistic cloud representations in radiation 
calculation (Cheng 2003) due to different time steps used in cloud microphysical processes (2 minutes) and in radiation calculation (1 hour). The effective cloud-droplet radius is decided by the same equations as (1) and (3) but the hybrid cloud water of (4) is used, instead of $C W P_{\text {prog. }}$.

In the simulation using Scheme-III, the process of liquid cloud water autoconversion, which converts water from clouds to rains due to cloud droplet coagulation, in the explicit moisture scheme is also modified. With a specified conversion coefficient $k_{l}$, the excessive cloud water is converted into rainwater with a rate of $k_{l}\left(q_{c}-q_{l, c r i t}\right)$, where $q_{c}$ is the cloud water mixing ratio and $q_{l, c r i t}$ is the a cloud water loading threshold. Instead of using a constant $q_{l, \text { crit }}\left(0.7 \mathrm{~g} \mathrm{~kg}^{-1}\right.$ in Rutledge and Hobbs $1983 ; 1.0 \mathrm{~g} \mathrm{~kg}^{-1}$ in Lin et al. 1983 ; and $0.5 \mathrm{~g} \mathrm{~kg}^{-1}$ in Dudhia 1989), we use the same and as Giorgi et al. (1999) who used RCM with the same spatial resolution $(60 \mathrm{~km})$ to simulate the EASM. The varies linearly with temperature, from $0.02 \mathrm{gm}^{-3}$ at $220 \mathrm{~K}$ to $0.1 \mathrm{gm}^{-3}$ at $265 \mathrm{~K}$ and from $0.1 \mathrm{gm}^{-3}$ at $265 \mathrm{~K}$ to $0.2 \mathrm{gm}^{-3}$ at $295 \mathrm{~K}$. These modifications are entitled to yield cloud water contents in line with the observations (Giorgi et al. 1999), obtaining more realistic results of cloud optical depth.

\subsection{Cloud Radiative Forcing}

To evaluate the performances of cloud schemes in radiation calculation, the CRF is taken as the major index for comparison. The CRF is defined as the difference in the outgoing radiative flux at the top of the atmosphere (TOA) between clear and cloudy-sky conditions. This macroscopic parameter has taken into account contributions from cloud cover, cloud optical depth, and cloud emissivity, providing direct and useful information about the cloud-climate interaction. The definitions of the shortwave and longwave CRF at the TOA are:

$$
\begin{aligned}
& S W C R F=-\left(S W F_{c l r}-S W F_{c l d}\right), \\
& L W C R T=L W F_{c l r}-L W F_{c l d},
\end{aligned}
$$

where $S W C R F$ represents the shortwave CRF; $L W C R F$, the longwave CRF; $S W F_{c l d}$, the net total-sky downward shortwave flux; $L W F_{c l d}$, the net total-sky upward longwave flux; $S W F_{c l r}$, the net clear-sky downward shortwave flux; and $L W F_{c l r}$, the net clear-sky upward longwave flux.

The effects of CRF can be simply categorized into a cloud albedo (cooling) effect and a cloud greenhouse (warming) effect, the latter is associated with the large cloud longwave absorptivity/emissivity and a colder cloud top temperature. Thus, based on the magnitudes of the shortwave and the longwave CRF, the optical depth and the vertical extent of clouds can be identified. Low-level clouds usually contain more cloud water and possess thicker cloud optical depth and cloud albedo, causing greater cloud albedo effect. A higher cloud top altitude usually associates with colder cloud top temperature, resulting in greater reduction in outgoing longwave radiation and thus a stronger greenhouse effect. Except for those tropical deep convection active regions, where shortwave CRF and longwave CRF almost cancel each other out (Ramanathan et al. 1987; Harrison et al. 1990; Kiehl 1994b; Collins et al. 1996; Tian and 
Ramanathan 2002), in general, the magnitude of shortwave CRF is larger than that of longwave $\mathrm{CRF}$, yielding a negative net CRF (cooling) of the atmosphere-earth system.

\subsection{Observation Data}

Station measurements of daily surface maximum and minimum temperatures and precipitations are obtained from the NCAR Data Support Section. Within the model inner domain, there are about 140 stations available for comparison with model simulations which are linearly interpolated to the station locations. In addition to the ground-based observations, satellite retrievals are also used to analyze the clouds and associated radiative properties. Because of the specific time frame (the summer of 1991), no individually comprehensive data set that includes all of the parameters of interest (e.g., cloud cover, shortwave CRF, and longwave $\mathrm{CRF}$ ) is available. In this study, we used a combination of different datasets, the cloud fractions from the International Satellite Cloud Climate Project (ISCCP) D2 series data (Rossow and Schiffer 1999), the longwave CRF from the Television Infrared Observation Satellite (TIROS) Optional Vertical Sounder data, and the shortwave CRF from the surface solar irradiance datasets (Bishop et al. 1997) for Sea-viewing Wide Field-of-view Sensor (SeaWiFS).

ISCCP D2 provides monthly mean cloud parameters, including cloud cover, cloud-top pressures and temperatures, cloud water paths, and cloud optical depths, at the horizontal resolution of $280 \mathrm{~km} \times 280 \mathrm{~km}$ (approximately $2.5^{\circ} \times 2.5^{\circ}$ ). Once the high clouds are seen, the clouds underneath cannot be identified accurately by satellites. Thus, due to abundant high cloud in the EASM, only high cloud and total cloud amounts are compared in this study. TIROS Vertical Sounder (TOVS) datasets provide parameters, such as cloud fractions, outgoing longwave radiation, surface pressures, vertical profiles of temperatures, and water vapor over the whole globe, to monitor and investigate local and periodic phenomena as well as long-term climate changes. The parameter needed in this study is a five-day-average longwave $\mathrm{CRF}$ with $1^{\circ} \times 1^{\circ}$ horizontal resolution.

To analyze the shortwave CRF of the 1991 EASM region, the data used here are from the surface solar irradiance datasets for the SeaWiFS Project (Hooker and Esaias 1993). Based on the algorithm of Bishop et al. (1997), the daily average surface incident solar irradiances (clearsky and total-sky incident solar irradiances) are calculated at a resolution of $0.5^{\circ}$. Since this surface solar irradiance dataset only provides direct downward solar radiation at the surface under both clear sky and total sky conditions, the surface albedo $\left(\alpha_{s}\right)$ is needed to estimate shortwave CRF at the surface. The net downward shortwave fluxes (the downward shortwave fluxes minus the upward ones) in (1) are estimated by multiplying direct downward solar radiation fluxes with surface absorption, $1-\alpha_{s}$. Therefore, in this study, shortwave CRF at the surface is computed by subtracting clear-sky incident solar irradiance from that of total-sky and then multiplying the result by surface absorption $\left(1-\alpha_{s}\right)$ :

$$
\begin{aligned}
(S W C R F)_{\text {sufface }} & =-\left(S W F_{c l r}-S W F_{c l d}\right)_{\text {surface }} \\
& \cong-\left(S W D F_{c l r}-S W D F_{\text {cld }}\right)_{\text {surface }} \times\left(1-\alpha_{s}\right),
\end{aligned}
$$


where $S W D F_{c l d}$ indicates the total-sky direct downward shortwave flux at the surface, $S W D F_{c l r}$ is clear-sky direct downward shortwave flux at the surface, and the subscript "surface" denotes surface fluxes. The SWDF biases of less than $20 \mathrm{~W} \mathrm{~m}^{-2}$ are measured on monthly timescales, and are mainly caused by uncertainties in aerosol optical depth. Because the fraction of solar radiation absorbed by clouds is very small, shortwave CRF at the surface is not much different from shortwave CRF at the TOA. Besides which, the greatest impact of shortwave CRF occurs at the surface, resulting in colder surface temperature, and lower sensible and latent heat fluxes. Hereafter, shortwave CRF at the surface is used for analyses.

In SUNYA RCM, cloud covers are calculated based on the assumption of random overlapping. High-level cloud covers indicate clouds occurring between the model top and $440 \mathrm{hPa}$. In ISCCP, cloud covers are decided by the occurrence of overcast pixels with highlevel clouds being identified based on cloud top pressure and cloud optical depth. When comparing model with satellite observations, direct use of cloud covers may lead to overestimation as high humidity near the model top can produce abundant high-level clouds of negligible optical properties. When we consider cloud-radiative effect, effective cloud covers are compared with the cloud covers of satellite observations.

\subsection{SUNYA Regional Climate Model}

SUNYA-RCM is developed based on the fifth-generation Pennsylvania State UniversityNational Center for Atmospheric Research Mesoscale Model version 2 (MM5, Grell et al. 1994) and has been used to study the scale-dependence of cloud-radiation interactions (Dudek, et al. 1996) and EASM (Leung et al. 1999; Gong and Wang 2000; Wang et al. 2000). Following Gong and Wang (2000) and Wang et al. (2000), the same model domain centering at $30^{\circ} \mathrm{N}$ and $120^{\circ} \mathrm{E}$ and extending $5040 \mathrm{~km} \times 3840 \mathrm{~km}$ horizontally with $60 \mathrm{~km}$ spatial resolution is used in this study. The vertical coordination extends from the surface to the pressure level of $10 \mathrm{hPa}$ and employs 23 sigma levels with resolution varying from $\sim 100 \mathrm{~m}$ in the planetary boundary layer (PBL) to $\sim 500 \mathrm{~m}$ in the free atmosphere. Objective analyses from the European Centre for Medium-Range Weather Forecasts (ECMWF)-Tropical Ocean Global Atmosphere (TOGA) are implemented to provide initial and external lateral boundary conditions. Data of 0000UT and 1200UT are linearly interpolated in space and time to give the lateral boundary conditions for driving the SUNYA-RCM. The 18-grid point buffer zone along with the linear interpolation function in the nudging procedure, showing good performances in the EASM simulations of Gong and Wang (2000), are adopted.

Several physical parameterization options of Gong and Wang (2000) and Wang et al. (2000) have been changed to more comprehensive ones. For surface-atmosphere interaction, the Simplified Simple Biosphere model (SSiB) and the Mellor-Yamada PBL scheme (Xue at al. 1996) are used respectively over land surface and ocean to account for the transfer of momentum, heat, and moisture. For radiation calculation, the CCM3 radiation model is used as mentioned in section 2.1. For cumulus convection, Grell's Heymsfield and Donner (1990) is added to the explicit mix-phase bulk microphysical moisture scheme (Dudhia 1989) to effectively remove the excessive cloud ice of the upper troposphere, shown in earlier works of the SUNYA-RCM (Leung et al. 1999). 


\section{CLOUD COVERS, CRF, AND SURFACE TEMPERATURES}

\subsection{Observations}

The 1991 Mei-Yu season over the Yangtze-Huai River valley was an extraordinary event due to its long duration (from May 18 to July 13, almost twice its climatological length) and severe floods. Following Lu et al. (1998), three major rain episodes during May 18 to 26 (Episode-I), June 2 to 20 (Episode-II), and June 30 to July 13 (Episode-III) over the YangtzeHuai river valley are defined to conduct analyses over the East China region $\left(105^{\circ}-122^{\circ} \mathrm{E}\right.$; $20^{\circ}-40^{\circ} \mathrm{N}$ ). Because each major rain episode occurred in different months, the monthly mean values of CRF, and cloud covers can indicate the cloud features of each rain episode. In this study, all "zonal means" refer to data averaged within the area, $105^{\circ}-120^{\circ} \mathrm{E}$.

According to observation, these major rain episodes exhibit heavy precipitation but with different cloud cover and CRF features. The intra-seasonal variations of clouds can be identified in Table 2, which shows the regional and monthly averaged shortwave and longwave CRFs and the high-level and total cloud covers over the east China region. A weaker longwave $\mathrm{CRF}$ of $+27.4 \mathrm{~W} \mathrm{~m}^{-2}$ associated with a stronger mean shortwave CRF of $-121.8 \mathrm{~W} \mathrm{~m}^{-2}$ in May turned into a stronger longwave CRF of $+36.2 \mathrm{~W} \mathrm{~m}^{-2}\left(+38.0 \mathrm{~W} \mathrm{~m}^{-2}\right)$ with a weaker shortwave CRF of $-111.3 \mathrm{~W} \mathrm{~m}^{-2}\left(-102.1 \mathrm{~W} \mathrm{~m}^{-2}\right)$ in June (July). The comparable total cloud covers (about $77 \%$ ) of each month came with noticeable difference in high-level cloud covers, a difference also shown in the intra-seasonal variations of cloud structures. Therefore, with the similar total cloud covers, the less high-level cloud covers $(20.9 \%)$ indicates either more low- or middle-level clouds or less cloud overlapping in May. This transition is consistent with the description of precipitation type given for the 1991 Mei-Yu by Lu et al.(1998). Since low-level clouds cause weaker longwave CRF and stronger shortwave CRF, the aforementioned intra-seasonal variation in cloud structures can well explain the intra-seasonal transition of CRF. The prevailing clouds in May are low-level clouds associated with thick optical

Table 2. Observed monthly means of the surface shortwave CRF, the TOA longwave CRF, and cloud covers of 1991 over the east China region, covering the area from $\sim 105^{\circ}$ to $122^{\circ} \mathrm{E}$ and from $\sim 20^{\circ}$ to $40^{\circ} \mathrm{N}$. Observed data are retrieved from satellite observation.

\begin{tabular}{|c|c|c|c|c|}
\hline & $\mathrm{SW} \operatorname{CRF}\left(\mathrm{W} \mathrm{m}^{-2}\right)$ & $\mathrm{LW}$ CRF $\left(\mathrm{W} \mathrm{m}^{-2}\right)$ & High Cloud $(\%)$ & Total Cloud (\%) \\
\hline May & -121.84 & +27.41 & 20.85 & 77.59 \\
\hline June & -111.31 & +36.24 & 34.38 & 77.44 \\
\hline July & -102.07 & +38.03 & 34.38 & 76.19 \\
\hline
\end{tabular}


depth, stronger shortwave CRF, and weaker longwave CRF, whilst in June and July high-level clouds associated with thinner optical depth, weaker shortwave CRF, and larger longwave CRF dominate.

Intra-seasonal variations in cloud structure and CRF are shown in Fig. 2 and Table 3. In Fig. 2, good correlation between zonal distributions of CRF and cloud cover are observed: the correlation coefficients of longwave CRF and high-level cloud covers are over $84 \%$, and those of shortwave CRF and total cloud covers are over $-74 \%$. The spatial correlation coefficients of $\mathrm{CRF}$ and cloud covers calculated from the monthly mean averaged data within the East China region are listed in Table 3. In addition to showing good correlation between longwave CRF
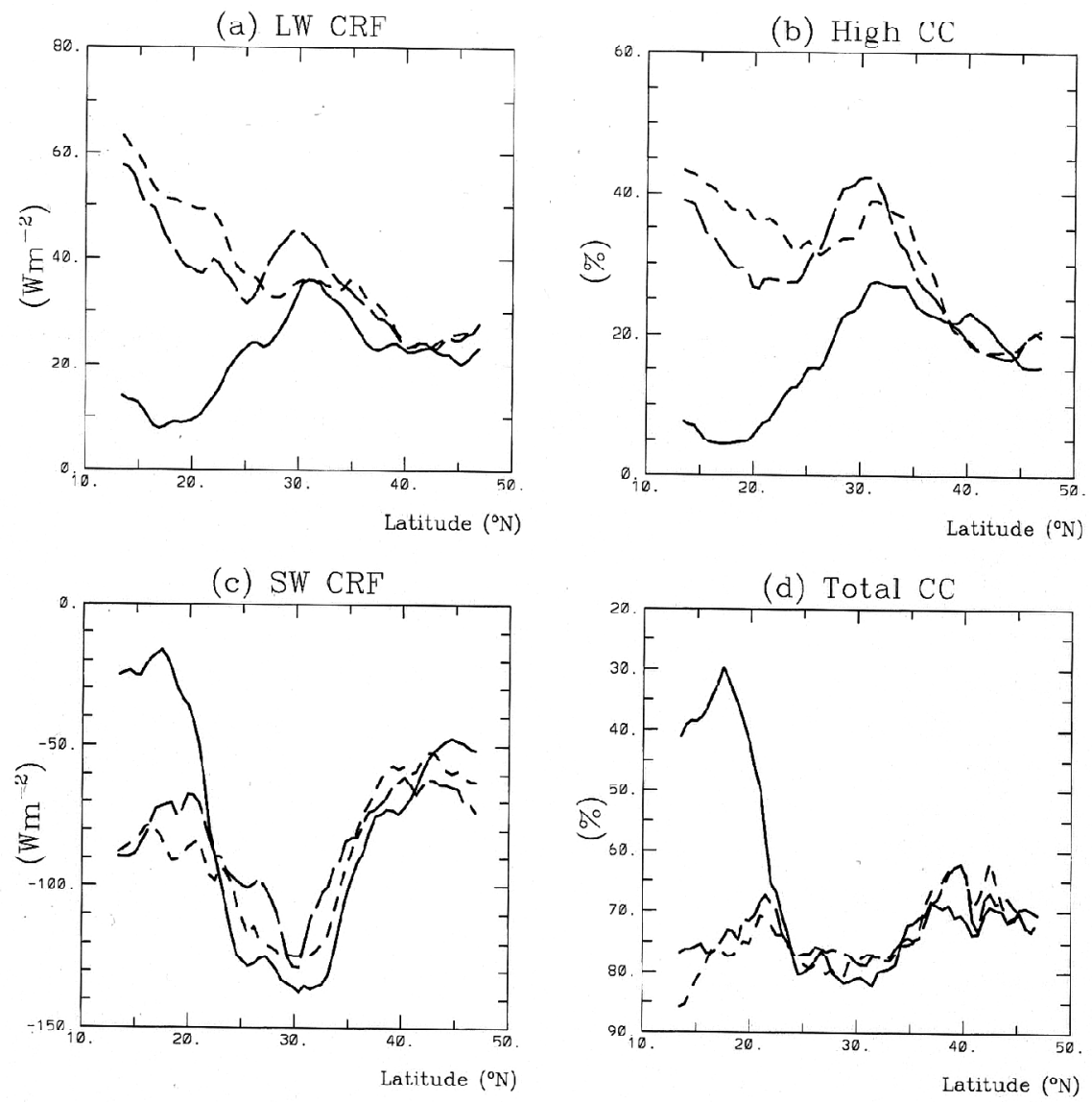

Fig. 2. The zonal (from $\sim 105^{\circ}$ to $122^{\circ} \mathrm{E}$ ) averages of the observed (a) longwave CRF at the TOA, (b) high cloud cover, (c) shortwave CRF at the surface, and (c) total cloud cover over Eastern China. Solid, dashed, and broken lines indicate, respectively, the meridional distributions in May, June, and July 1991. 
Table 3. Spatial correlation coefficients between observed CRF and cloud cover for May, June, and July.

\begin{tabular}{ccccccc}
\hline \hline & \multicolumn{3}{c}{ High Cloud } & \multicolumn{3}{c}{ Total Cloud } \\
\cline { 2 - 7 } & May & June & July & May & June & July \\
\hline LW CRF & $83 \%$ & $60 \%$ & $80 \%$ & $69 \%$ & $35 \%$ & $73 \%$ \\
SW CRF & $-37 \%$ & $-47 \%$ & $-73 \%$ & $-85 \%$ & $-83 \%$ & $-74 \%$ \\
Total Cloud & $52 \%$ & $61 \%$ & $86 \%$ & - & - & - \\
\hline
\end{tabular}

and high-level cloud cover and between shortwave CRF and total cloud cover, the transition of dominant cloud type as mentioned in the previous paragraph can also be identified in Table 3 . The increasing high-level clouds in June and July not only dominated total cloud covers but also dominated shortwave CRF. As time passed, the magnitude of correlation coefficients between high-level clouds and shortwave CRF increased from $37 \%$ to $73 \%$, and those between high-level clouds and total clouds increased from $52 \%$ to $86 \%$. On the other hand, weakening correlation coefficients between shortwave CRF and total cloudiness can be explained by the smaller optical depths of the increasing high-level clouds.

Although all are characterized by deep convection, the regions of the EASM, the Asian monsoon (Rajeevan and Srinivasan 2000), and the tropical convection (Ramanathan et al. 1987; Harrison et al. 1990; Kiehl 1994b; Collins et al. 1996) have different CRF features. Shortwave CRF only reaches $-100 \mathrm{~W} \mathrm{~m}^{-2}$ in the tropical Pacific region but can be smaller than $-140 \mathrm{~W} \mathrm{~m}^{-2}$ in both the Asian and the EASM regions (Fig. 3a). Rajeevan and Srinivasan (2000) point out that the larger high cloud amount and associated thicker cloud optical depth (greater than 14) are the main reasons why shortwave CRF of the Asian monsoon region is stronger than that of the tropical Pacific. On the other hand, longwave CRF can be greater than +100 and $+80 \mathrm{~W} \mathrm{~m}^{-2}$ in the tropical Pacific region and the Asian monsoon region, respectively, but barely reaches $+60 \mathrm{~W} \mathrm{~m}^{-2}$ in the EASM region. Hartmann et al. (2001) mentioned that the prevailing high clouds, with tops higher than $180 \mathrm{hPa}$ and optical depths less than 4 , are the main factor causing the weaker shortwave CRF, and stronger longwave CRF and thereby maintaining the near-zero net CRF over the western Pacific warm pool, resulting in a $1: 1$ ratio of longwave to shortwave CRF intensity. However, stronger shortwave CRF and weaker longwave CRF occurred in the EASM region, resulting in a strong and negative net CRF. The ratios of longwave to shortwave CRF intensity are much smaller, about $1: 4.5$ in May, $1: 3$ in June, and $1: 2.7$ in July, in the EASM region. The larger ratio and larger longwave CRF usually imply abundant high-level clouds and stronger convection. Thicker cloud optical depth is responsible for stronger SW CRF; where as, warmer cloud-top temperatures and less cloud cover and water content in high-level clouds may cause weaker LW CRF. 


\subsection{Model Simulations}

Based on monthly means over land surface in the inner domain, scatter diagrams of observed and simulated shortwave and longwave CRF are shown in Fig. 3. The tilted straight lines in Fig. 3 indicate the cancellation effect between shortwave CRF and longwave CRF. In Fig. 3a, the observed data points of May can be easily separated from those of June and July due to their smaller longwave CRF (less than $30 \mathrm{~W} \mathrm{~m}^{-2}$ ). Similar to observation, most of the simulated data still reside in the same area where the ratios of longwave to shortwave CRF intensity are smaller than 1:1 and show the distinctive separation of May from June and July.

(a) Observ.

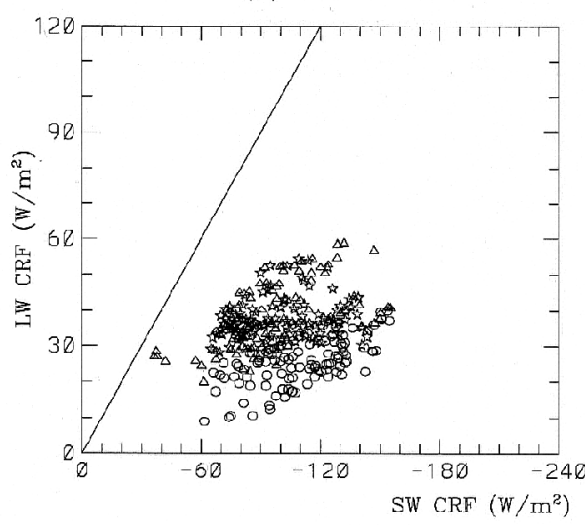

(c) EX prog

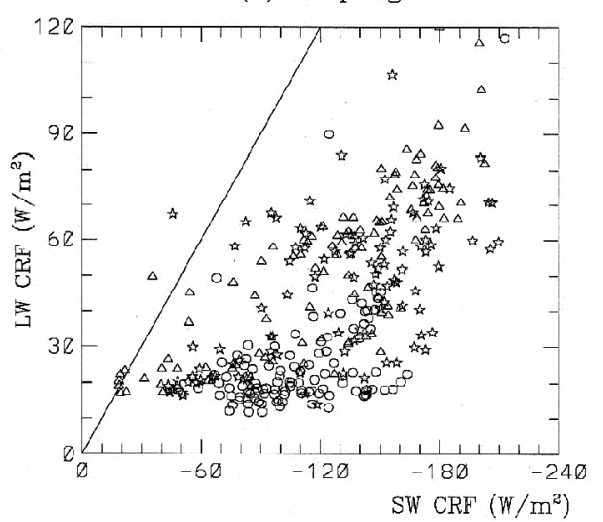

(b) EX diag

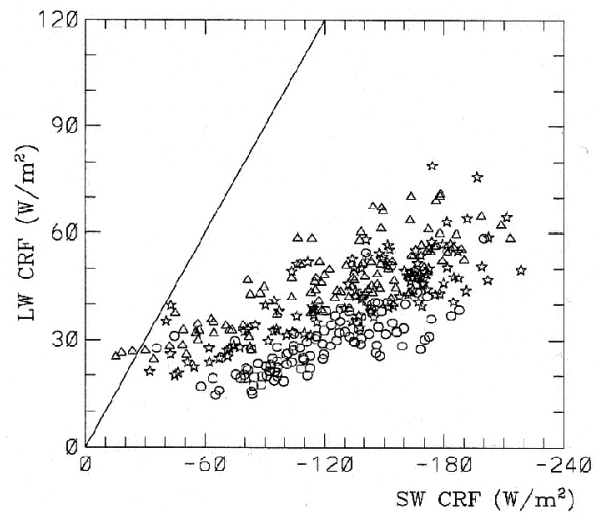

(d) EX hyb

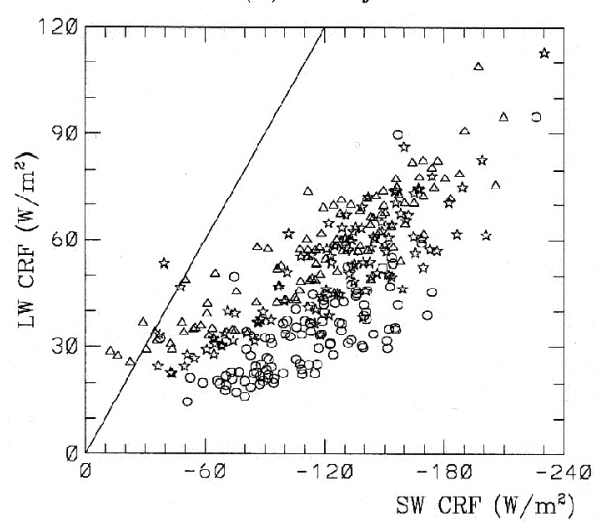

Fig. 3. The scatter diagrams of the monthly mean surface shortwave CRF and TOA longwave CRF (unit: $\mathrm{W} \mathrm{m}^{-2}$ ) of the (a) observation, (b) the EX_diag, (c) the EX_prog, and (d) the EX_hyb. Circles, triangles, and stars represent the data collected in May, June, and July, respectively. Straight line with slope -1 represents the cases with the same absolute values of longwave CRF and shortwave CRF. 
However, all simulations have broader scattering than the observations. The data points of EX_prog and EX_hyb spread more dispersively than those of observation and EX_diag.

Figures 4 and 5 show the time series of zonal averaged longwave and shortwave CRF distributions, respectively, for May 1 - July 29. All rain episodes can be identified except the ambiguous break with strong CRF between Episode I and Episode II. Overall, without considering the results in the buffer zone (southward of $\sim 20^{\circ} \mathrm{N}$ and northward of $\sim 38^{\circ} \mathrm{N}$ ) the model
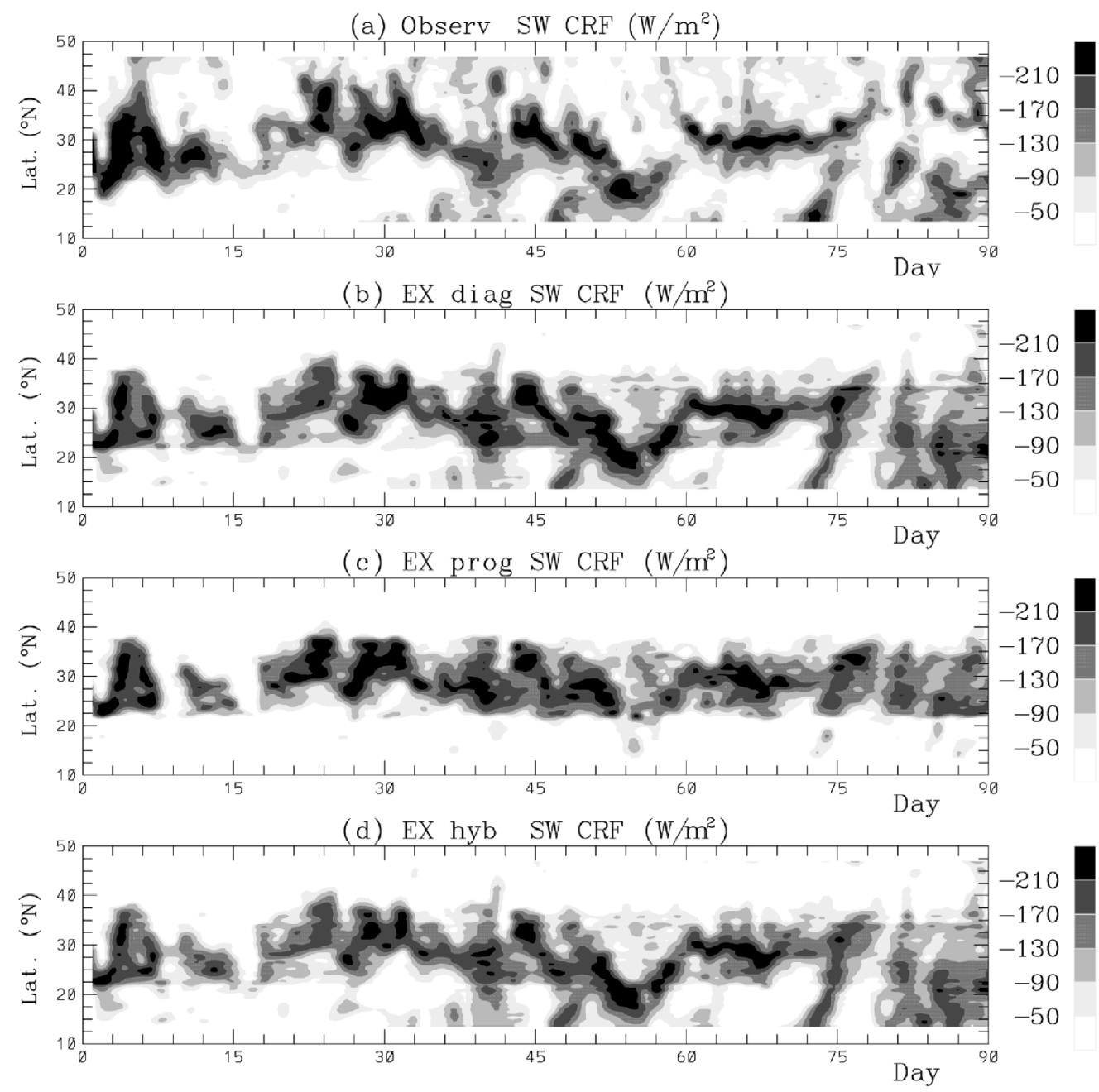

Fig. 4. Hövmöller diagrams from May 1 (day 1) to July 28 (day 90) 1991 of the simulated zonal mean surface shortwave CRF of (a) observation, (b) EX_diag, (c) EX_prog, and (d) EX_hyb. Data is with 1-day temporal resolution. 

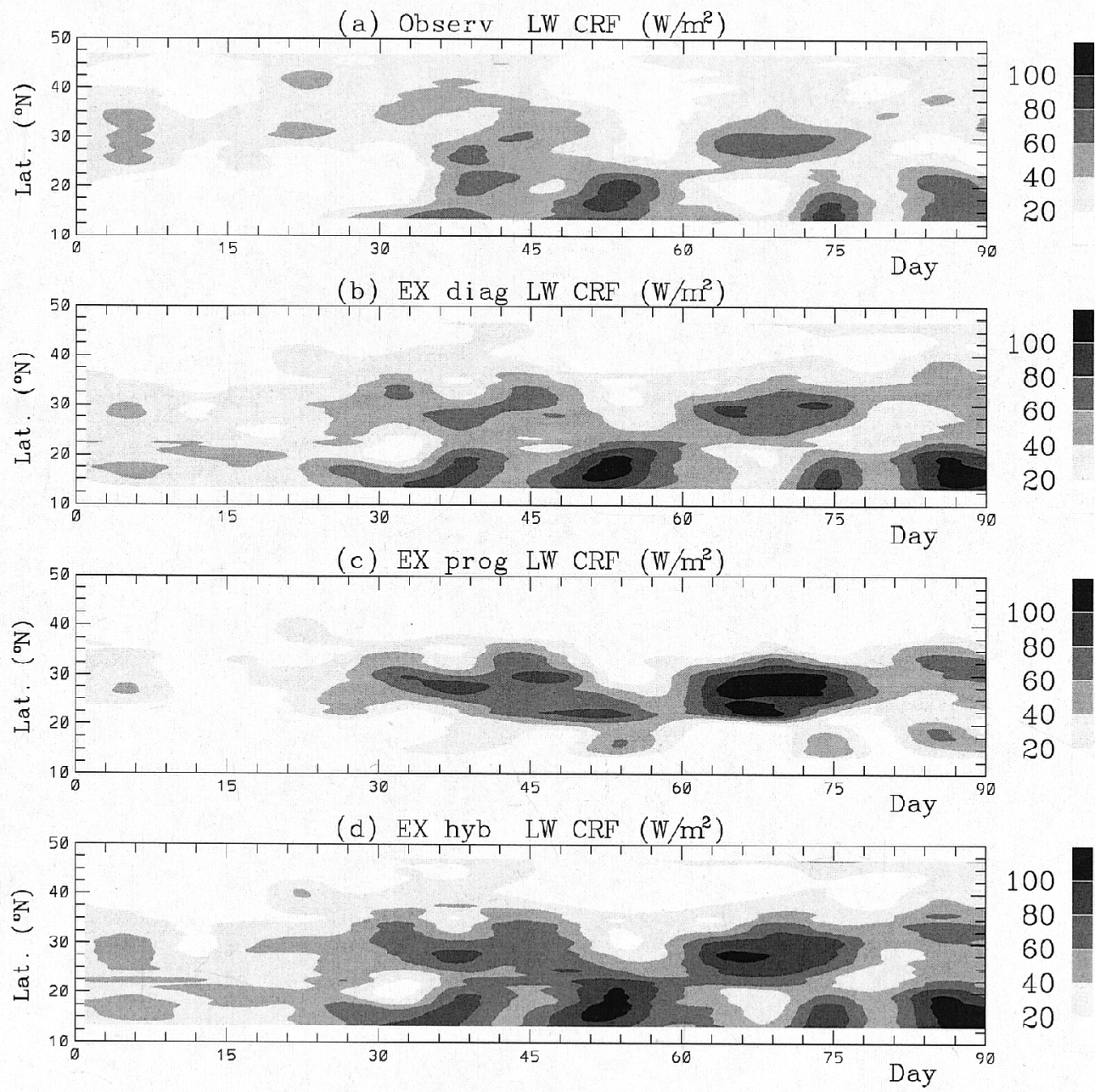

Fig. 5. Hövmöller diagrams from May 1 (day 1) to July 28 (day 90) 1991 of the simulated zonal mean TOA longwave CRF of (a) observation, (b) EX_diag, (c) EX_prog, and (d) EX_hyb. Data is with 5-day temporal resolution.

captures the characteristics of the rain events, the transitions, and the spatial distributions of CRF for all simulations. It is noted that shortwave CRF of prognostic clouds (Fig. 4c) is almost negligible in the buffer zone where the thermodynamic state and circulation are relaxed to lateral boundary conditions. Lateral boundary conditions are interpolated from the ECMWF data where humidity over grids of size $2.5^{\circ} \times 2.5^{\circ}$ seldom reaches saturation, limiting the formation of prognostic clouds. However, clouds still can be diagnosed in the sub-saturated 
buffer zone by Scheme-I although their radiative effects (Fig. 4b) are also small in the area northward of $38^{\circ} \mathrm{N}$ where the precipitable water (which decides cloud water path) and relative humidity are small.

Due to the consideration of subgrid-scale clouds, Schemes I and III result in better spatial distributions of CRF than Scheme-II does (Figs. 4, 5). However, Scheme-I still overestimates both shortwave and longwave CRF in June and July (Table 4). The shortwave CRF overestimations of Scheme-I mainly take place in areas where deep convection is inactive. Scheme-II overestimates shortwave CRF more than Scheme-I, with about $-31 \mathrm{~W} \mathrm{~m}^{-2}$ in June and $-39 \mathrm{~W} \mathrm{~m}^{-2}$ in July, in the convection inactive areas (Fig. 4c). Among all the experiments, Scheme-III results in the smallest shortwave CRF biases, $-19 \mathrm{~W} \mathrm{~m}^{-2}$ in June and $-26 \mathrm{~W} \mathrm{~m}^{-2}$ in July (Table 4). The smaller shortwave CRF biases simulated by Scheme-III are primarily attributed to improvement in precipitation inactive areas (not shown). With modification in the autoconversion rate of microphysics and consideration for fractional diagnostic cloud covers, hybrid cloud water and cloud optical depth are effectively reduced, minimizing shortwave CRF biases in EX_hyb. Because shortwave distinction is more sensitive to clouds with smaller optical depth, the strength of shortwave CRF decreases more in rain free areas than in rainy areas where cloud optical depth is usually very thick. As for longwave CRF, all schemes overestimate it in June and July while Scheme-II underestimated it in May. Cooler cloud top temperature and an abundant ice water path are most likely responsible for the longwave overestimation.

Table 4. The observed monthly and regional mean CRF and the simulated CRF deviations, in respect to the observed ones, of over the east China region for May, June, and July. (Unit: $\mathrm{W} \mathrm{m}^{-2}$ )

\begin{tabular}{ccccccc}
\hline \hline & \multicolumn{3}{c}{ Surface SW CRF } & \multicolumn{3}{c}{ TOA LW CRF } \\
\cline { 2 - 7 } & May & June & July & May & June & July \\
\hline Observation & -122 & -111 & -102 & 27 & 36 & 38 \\
EX_diag & -4 & -32 & -31 & +3 & +8 & +12 \\
EX_prog & +5 & -31 & -39 & -4 & +15 & +24 \\
EX_hyb & +6 & -19 & -26 & +6 & +18 & +24 \\
\hline
\end{tabular}

As CRF primarily impacts climate through changes in surface heat flux, CRF biases can greatly influence surface temperature. Temporal variations in regional averages of surface maximum and minimum temperatures, and precipitation are well simulated by the model(Fig. 6). However, not only are these trends well simulated, but trends in spatial standard deviation of 
(a) $\mathrm{T}_{\max }, \mathrm{T}_{\text {min }}$, \& Rain $\left({ }^{\circ} \mathrm{C}\right)$

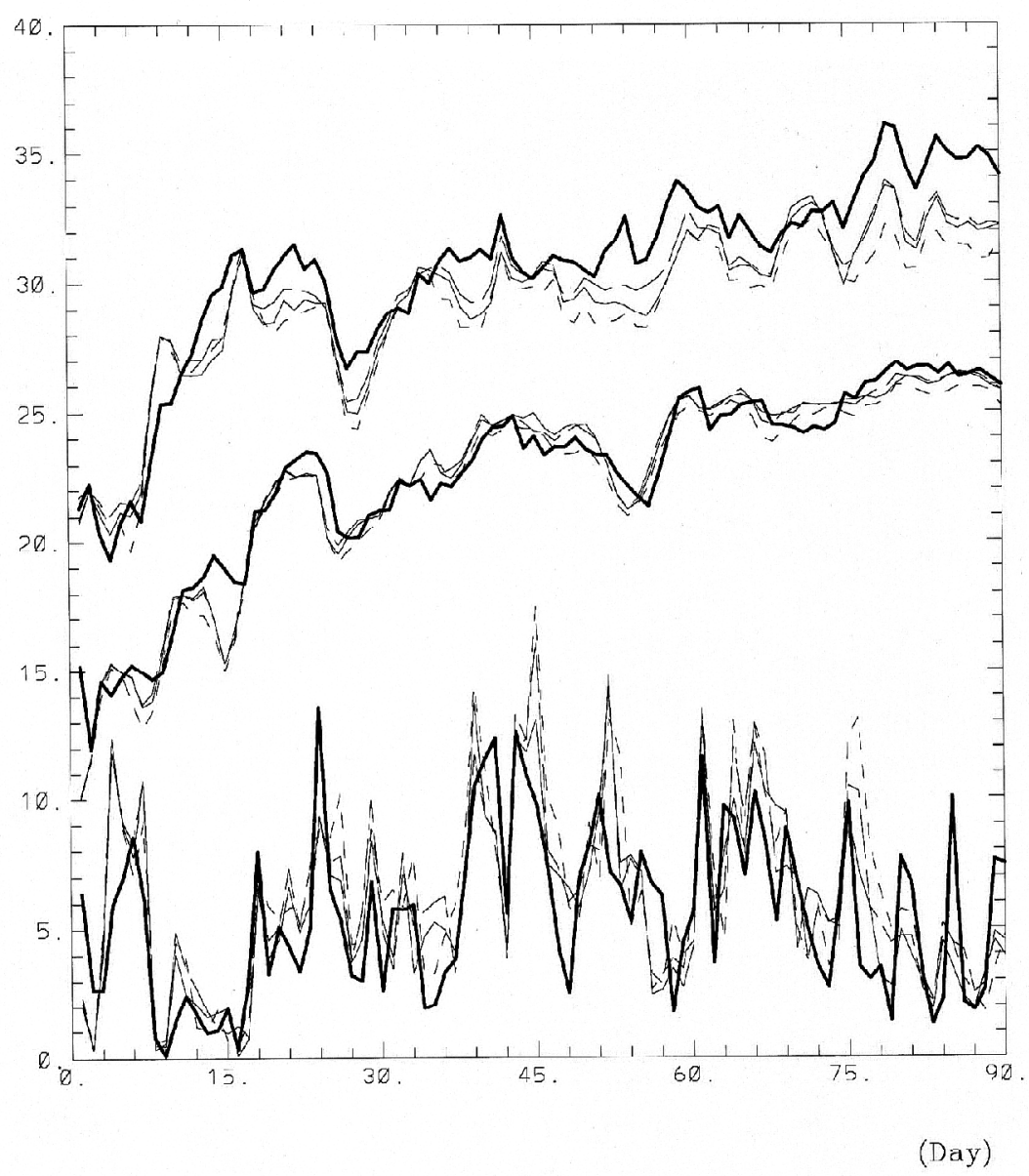

Fig. 6. Time series of the regional (from $\sim 105^{\circ}$ to $122^{\circ} \mathrm{E}$ and from $\sim 20^{\circ}$ to $40^{\circ} \mathrm{N}$ ) averaged land surface maximum and minimum temperatures $\left({ }^{\circ} \mathrm{C}\right)$, and precipitation $\left(\mathrm{mm} \mathrm{day}^{-1}\right)$. Bold solid, solid, dashed, and broken lines indicate the data of observation, EX_diag, EX_prog, and EX_hyb, respectively.

these surface variables are also well simulated (not shown); although, model biases in maximum temperature and precipitation do exist. The model underestimates surface maximum temperatures most of the time, especially under Scheme-II. Scheme-III (with seasonal and regional averaged bias of $-0.87^{\circ} \mathrm{C}$ and root mean square error of $3.33^{\circ} \mathrm{C}$ ) does a better performance than Scheme-I (with $-1.17^{\circ} \mathrm{C}$ bias and $3.42^{\circ} \mathrm{C}$ root mean square error) and Scheme-II (with $-1.61^{\circ} \mathrm{C}$ bias and $3.9^{\circ} \mathrm{C}$ root mean square error) do. The root mean square error (RMSE) 
of a variable $\mathrm{x}$ is defined as:

$$
R M S E=\sqrt{\frac{\sum_{i=1}^{N}\left(x_{m o d, i}-x_{o b s, i}\right)^{2}}{N}},
$$

where the subscript obs denotes the observations; mod, the corresponding model results; and $i$ and $N$, the index and the total number of sampled data. Similar to the conditions of shortwave $\mathrm{CRF}$, the surface maximum temperatures also have larger cold biases during the Mei-Yu breaks (e.g., day 51 to 60 and day 75 to 90). Figure 7 shows shortwave CRF biases along with surface maximum temperature. The shortwave CRF biases and temperature biases show a correlation coefficient greater than $86 \%$. This suggests improvement in shortwave CRF simulation would result in improved surface maximum temperature simulation.

Although Scheme-III results in smaller shortwave CRF biases, it results in larger longwave CRF overestimation because of the thick high-level clouds caused by considering a larger prognostic cloud ice content, and enhanced convection activity caused by the feedback of larger surface heat fluxes. However, biases and differences in surface minimum temperatures among different experiments are small. The results show that using different cloud schemes has a greater impact on maximum temperature than on minimum temperature and precipitation. Note that the surface minimum temperature is related to longwave CRF at the surface more than to that at the TOA. In our experiments, the surface longwave CRF differences between experiments are much smaller than surface shortwave CRF differences. Moreover, the positive correlation between maximum temperature biases and minimum temperature biases in our simulations is another reason for smaller changes in minimum temperature, i.e., a cooler daytime maximum temperature would tend to weaken the cloud greenhouse effect the following night. Also, the temperature feedback of longwave radiation can alleviate changes in the surface energy budget.

\section{SURFACE ENERGY BUDGET AND DIURNAL CYCLE}

A negative shortwave CRF implies a reduction in solar radiation reaching the surface, resulting in cooler surface temperatures, which subsequently decrease surface sensible heat and latent heat fluxes, greatly impacting atmospheric circulation. In our simulations, almost all decreases in these surface heat fluxes compensate decreases in the surface radiative fluxes. This feedback of surface flux changes to the atmosphere is larger and more profound than cloud radiative forcing in the atmosphere. Thus, it is worth examining responses of surface energy balance components (ground temperature, radiative flux, and fluxes of sensible heat and latent heat) to the model using different cloud schemes. Data analyzed in this section are regional averages and departures from reference simulation (EX_diag) over land surface within the model's inner domain.

Figure 8 shows the time series of net CRF, net surface energy balance (with the sum of surface sensible and latent heat fluxes being subtracted from the sum of surface shortwave and 
(a) $\mathrm{T}_{\max }$ Bias $\left({ }^{\circ} \mathrm{C}\right)$

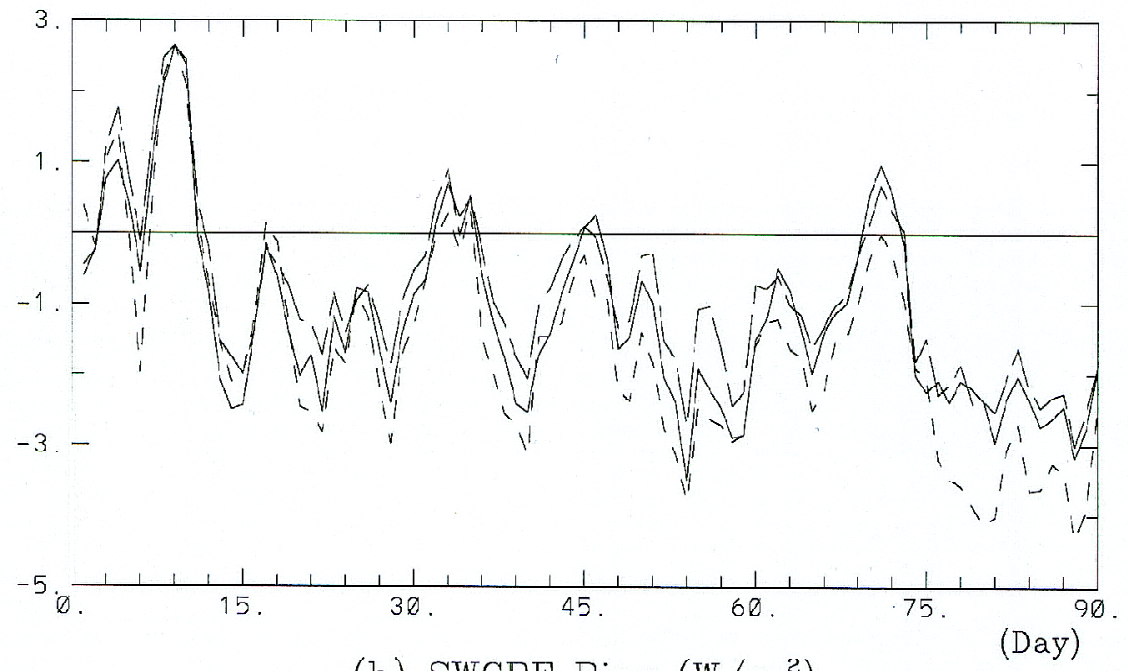

(b) SWCRF Bias $\left(W / m^{2}\right)$

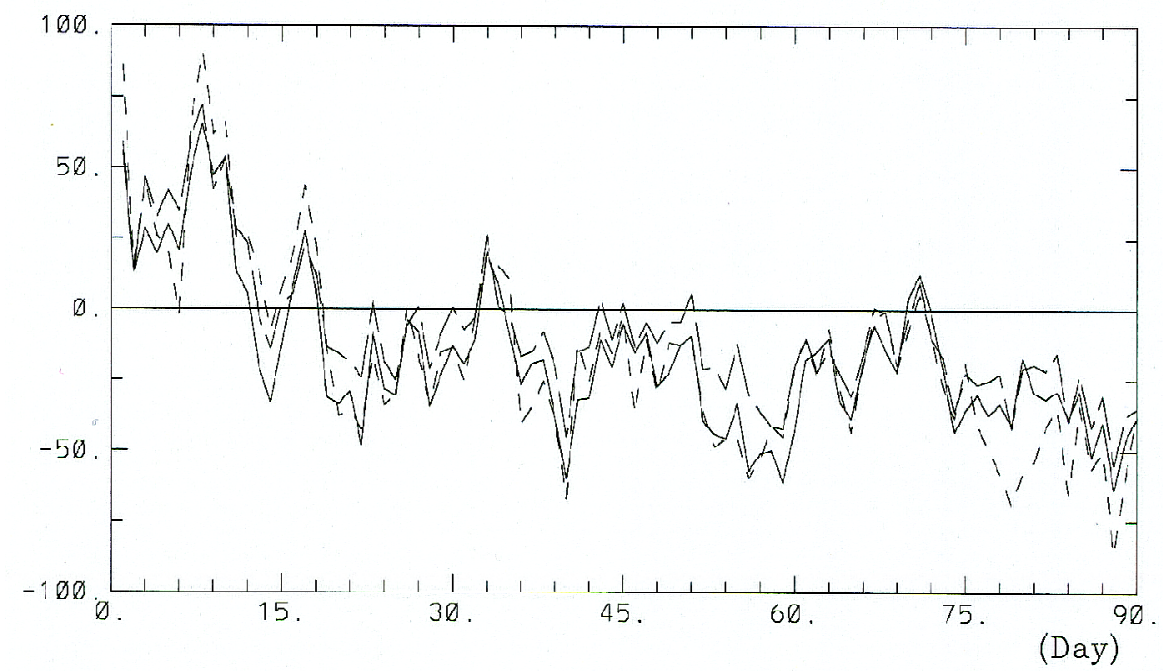

Fig. 7. Time series of the regional averaged (a) surface maximum temperature, and (b) shortwave CRF biases from observations. Bold solid, solid, dashed, and broken lines indicate the data of observation, EX_diag, EX_prog, and EX_hyb, respectively.

longwave radiative fluxes), and ground temperature departures at the surface. Fluctuations in net surface energy balance departures (Fig. 8b) explain fluctuations in ground temperature departures (Fig. 8c) very well. Fluctuations in surface net radiative flux and surface total heat flux departures (the sum of surface sensible and latent heat fluxes), not shown, resemble the 

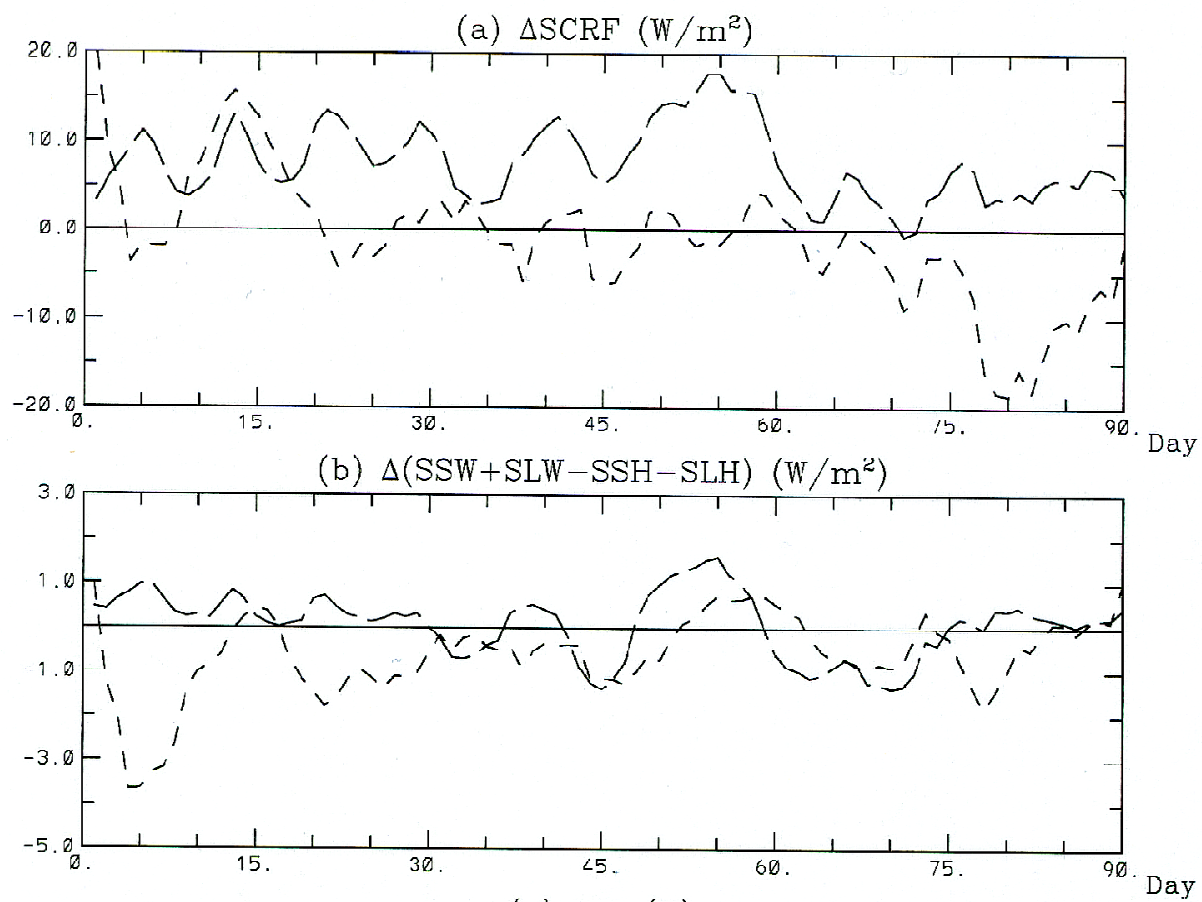

(c) $\Delta \mathrm{Tg}(\mathrm{K})$

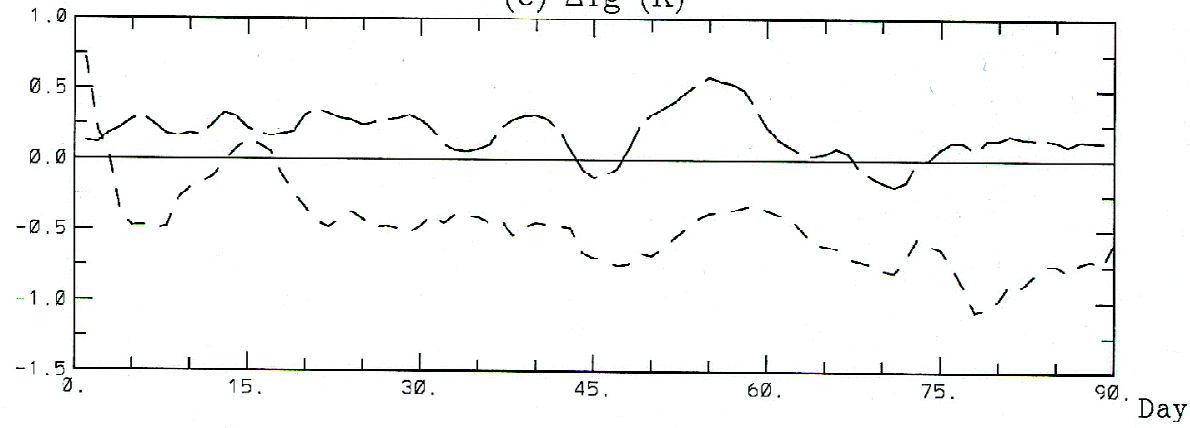

Fig. 8. The time series of the departures (from results of EX_diag) of regional averaged (a) net CRF at the surface, (b) net surface energy balance, and (c) ground temperature. Dashed and broken lines present the results of EX_prog, and EX_hyb, respectively.

results shown in Fig. 8a, indicating that the role of CRF is very critical in the surface energy budget. Magnitudes of related variables are listed in Table 5, showing seasonal and regional averages in the simulation of EX_diag, and departures of these averages in other simulations from that of EX_diag. The reduction in the surface energy supply caused by CRF is about 
Table 5. Seasonal and regional averages of surface shortwave CRF and related land surface variables over land within the model's inner domain.

\begin{tabular}{cccc}
\hline \hline & EX_diag & EX_prog & EX_hyb \\
\hline Surface CRF $\left(\mathrm{W} \mathrm{m}^{-2}\right)$ & -102.88 & -1.02 & +7.80 \\
Surface LH $\left(\mathrm{W} \mathrm{m}^{-2}\right)$ & 80.88 & +0.34 & +6.89 \\
Surface SH $\left(\mathrm{W} \mathrm{m}^{-2}\right)$ & 41.93 & -0.64 & +0.82 \\
Net surface energy balance $\left(\mathrm{W} \mathrm{m}^{-2}\right)$ & 7.91 & -0.61 & +0.08 \\
Ground Temperature $\left({ }^{\circ} \mathrm{C}\right)$ & 24.38 & -0.49 & +0.18 \\
\hline
\end{tabular}

$-100 \mathrm{Wm}^{-2}$. The land surface responds to the shortage of radiation gain with reduced ground temperature, and energy losses through changes in surface heat fluxes. Departures in surface total heat flux reduction are of similar magnitude to departures in surface net CRF (Table 5) and have good temporal correlation.

In addition to variation in daily means, we also examine below diurnal variation in seasonal means of normalized data. Normalized data are data with daily means having been subtracted before being divided by daily standard deviations. Therefore, diurnal cycles will not be dominated by data from those days with large variations. Diurnal variations in net surface radiative flux, CRF, and surface total heat flux departures also resemble each other (not shown), indicating that surface total heat flux responds over time offsetting changes in surface radiative flux. Figure 9a shows that different cloud schemes result in different diurnal variations in surface net incoming radiative fluxes, which are strongly related to diurnal variation in cloud optical depth (Fig. 9b). Surface incoming radiation reaches a maximum about one hour later in EX_prog than in EX-diag. Diurnal cycles of normalized column liquid cloud optical depths are shown in Fig. 9b, showing the diurnal cycle difference between diagnostic and prognostic clouds. To investigate the reason behind this difference, the diurnal variations of thermodynamic and cloud related fields are analyzed. Because the major contribution of cloud optical depth comes from clouds in the lower troposphere, which are directly affected by surface heat fluxes, we focus on diurnal cycles of thermodynamic states and cloud fields of the lower troposphere (from the surface to the sigma level of 0.5) below.

Through turbulence mixing, surface heat fluxes greatly affect atmospheric heating, moistening, and consequent cloud formation. Figure 10 shows the vertical distributions of the regional and seasonal averaged diurnal cycles of normalized (a) turbulence heating rate, (b) turbulence moistening rate, (c) air temperatures, (d) water vapor mixing ratio, (e) relative humidity, and (f) predicted liquid cloud water mixing ratio simulated in EX_diag. Although these diurnal cycles in Fig. 10 show similarity among different experiments (not shown), the diurnal cycles of cloud fields determined by the three cloud schemes for radiation calculation 


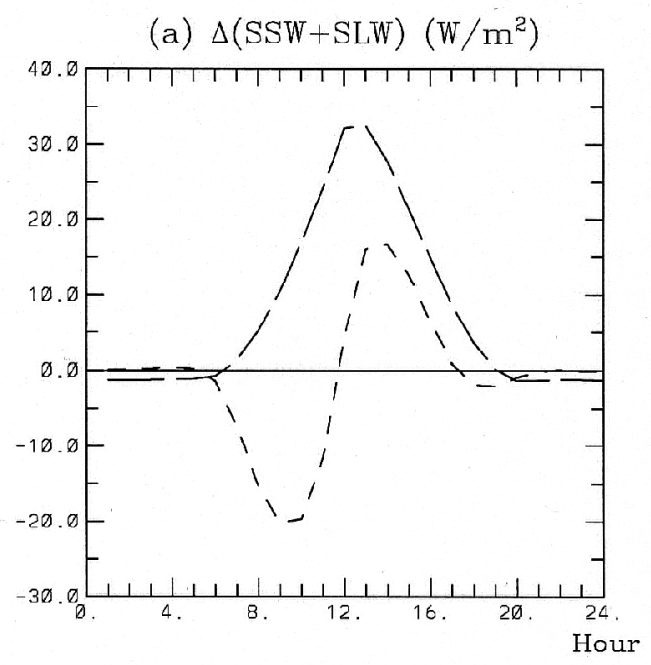

(b) Tau

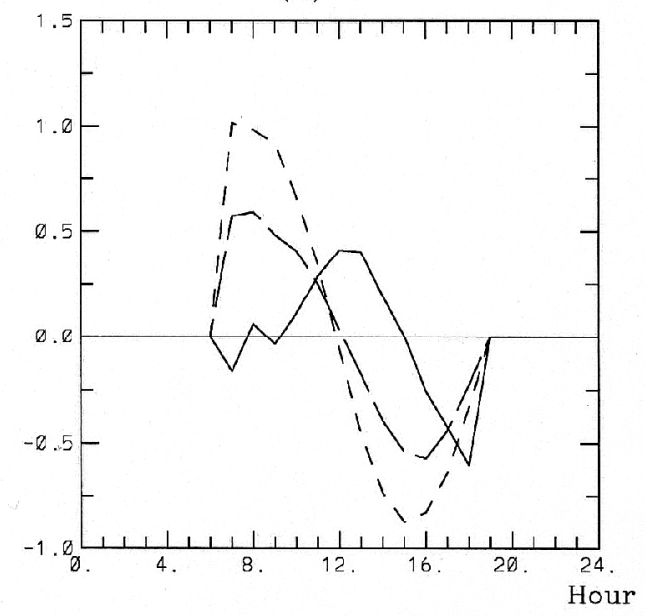

Fig. 9. The diurnal cycles of the regional and seasonal averaged (a) surface radiative flux departures from that of EX_diag $\left(\mathrm{W} \mathrm{m}^{-2}\right)$ and (b) normalized liquid water optical depth. Solid, dashed and broken lines indicate the results of EX_diag, EX_prog, and EX_hyb, respectively.

are different from each other. In Fig. 10, the upward propagating patterns of diurnal cycles in the lower troposphere (primarily lower than $\sim 800 \mathrm{hPa}$ ) show the responses of the atmosphere to the surface heat fluxes. It clearly shows that the diurnal variations of temperature and vapor are dominated by the heating (Fig. 10a) and moistening (Fig. 10b) due to turbulence mixing in the PBL.

Due to variations in temperature and water vapor, the resultant diurnal cycle of relative humidity also shows upward propagating characteristics in the lower troposphere (Fig. 10e) 
but with different phase from that of temperature and water vapor. Relative humidity is the key parameter to decide the diagnostic cloud cover and grid-box mean cloud water path used in radiation calculation. In EX_diag, except for the lowest three layers where no clouds are considered for radiation calculation, the figures of diurnal cycles of normalized cloud cover (Fig. 11a) and cloud water path for radiation calculation (Fig. 11b) resemble that of relative humidity (Fig. 10e). Note that the diurnal variation pattern of prognostic cloud water (Fig. 10f) is different from that of relative humidity and cloud cover, showing the inconsistency between the diagnostic and prognostic clouds.

(a) DHTUR

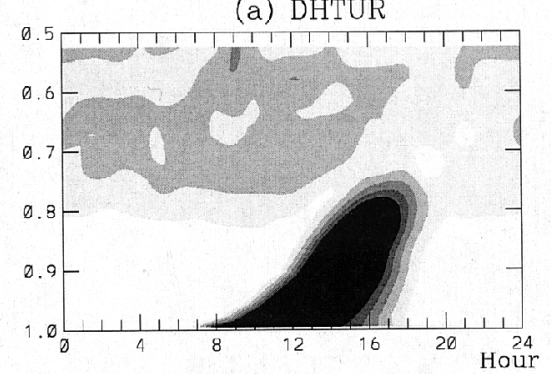

(c) Tomp.

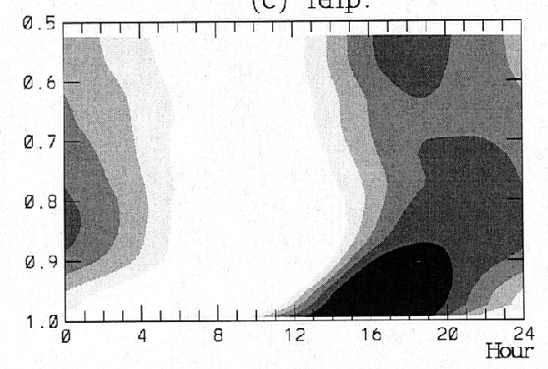

(e) $\mathrm{RH}$

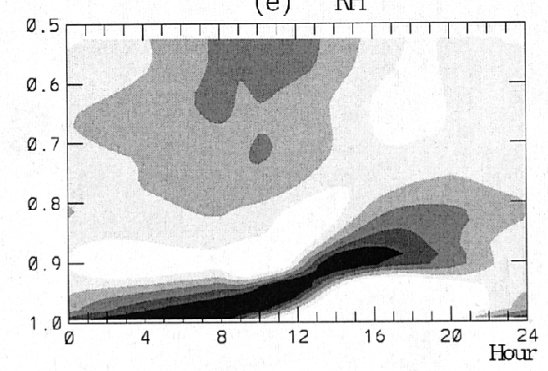

(b) DQTUR
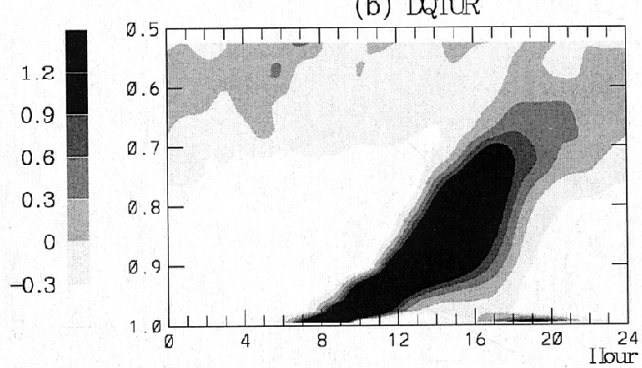

(d) Vapor
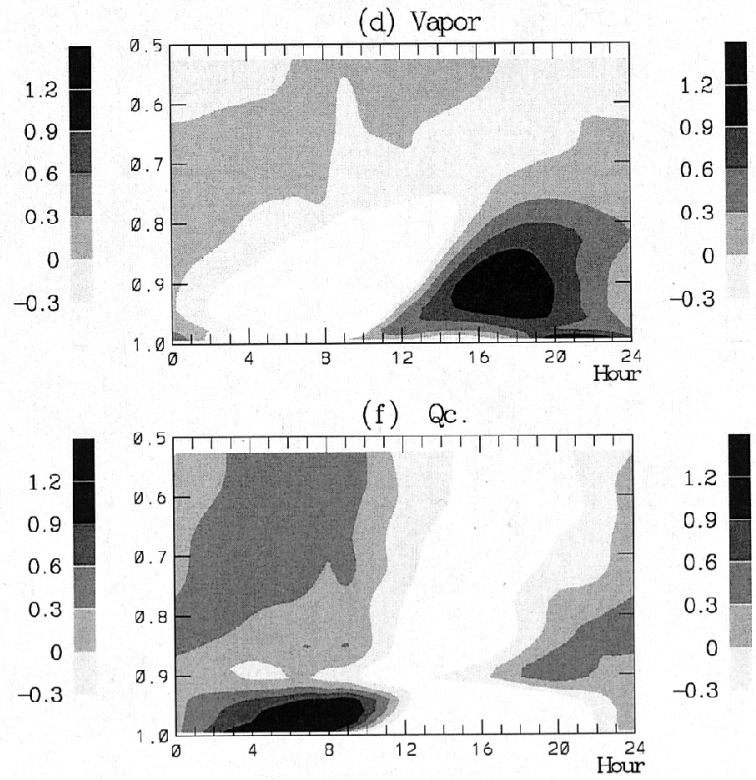

1.2

0.9

0.3

$-0.3$

(f) $\mathrm{Qc}$.
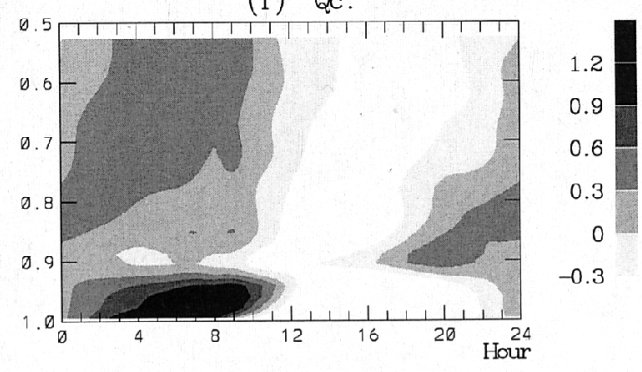

Fig. 10. The vertical distributions of the regional and seasonal averaged diurnal cycles of normalized (a) turbulence heating rate, (b) turbulence moistening rate, (c) air temperatures, (d) water vapor mixing ratio, (e) relative humidity, and (f) predicted liquid cloud water mixing ratio simulated by EX_diag. 

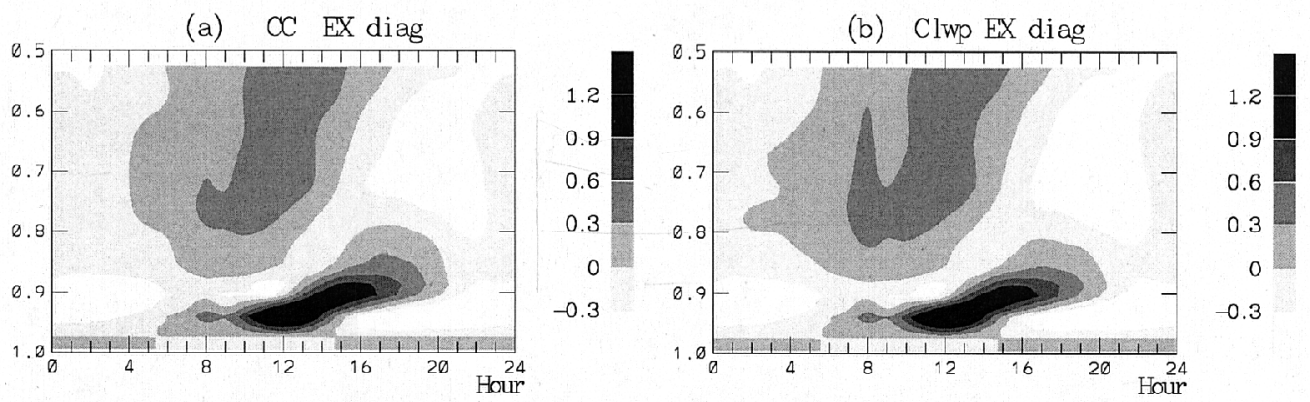

(c) $\propto$ EX prog
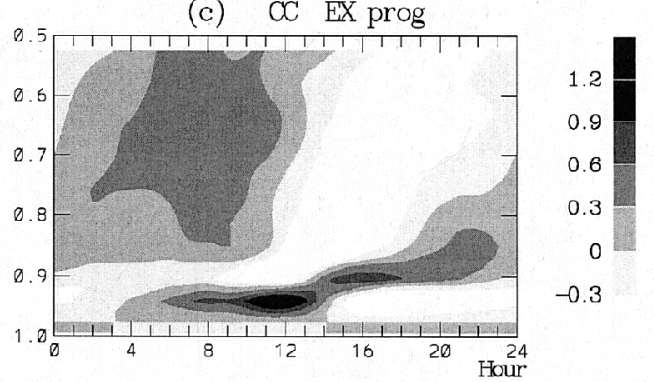

(d) Clwp EX prog
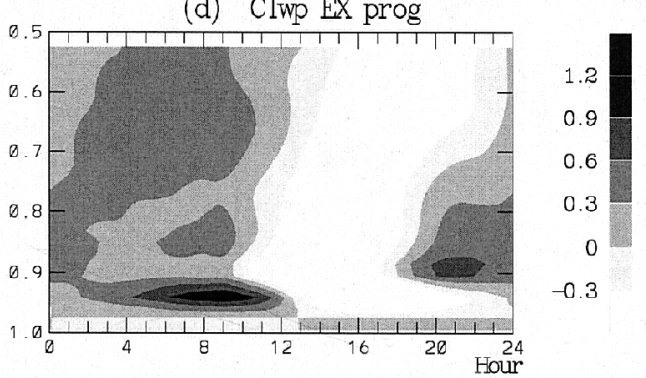

(e) Clwp EX hyb
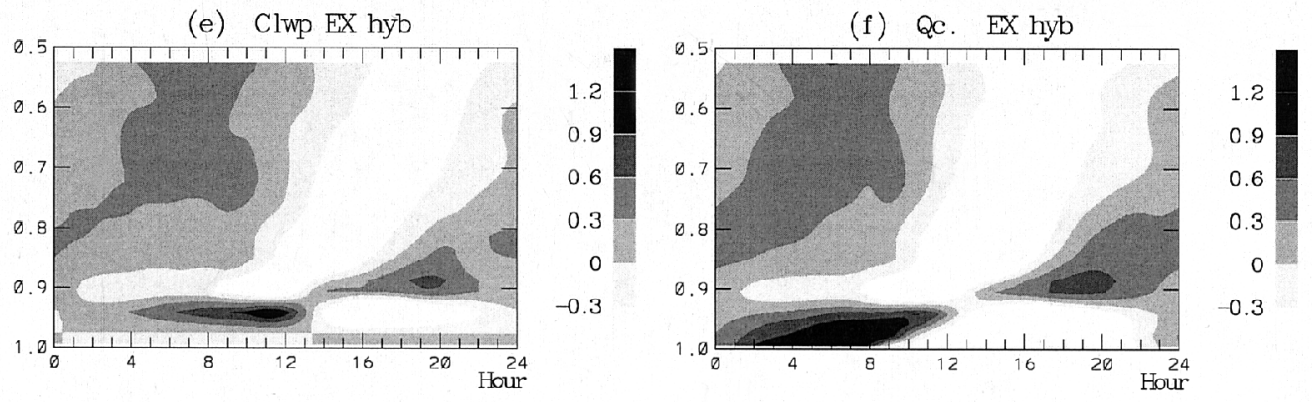

Fig. 11. The vertical distributions of the regional and seasonal averaged diurnal cycles of the normalized cloud cover of (a) EX_diag and (c) EX_prog; the normalized cloud water path for radiation calculation in (b) EX_diag, (d) EX_prog, and (e) EX_hyb; and (f) the normalized prognostic cloud water mixing ratio in EX_hyb.

In EX_prog at the layer from $\sim 900$ to $\sim 800 \mathrm{hPa}$, diurnal variation of cloud water path (Fig. 11d) is different from that of prognostic cloud cover (Fig. 11c) which is similar to that of relative humidity (similar to Fig. 10e), indicating that the high relative humidity in the afternoon may increase the occurrences of prognostic clouds but does not increase the in-cloud cloud water content. Given this, Scheme-II can simulate the generation of more cloud albeit with less cloud water in the afternoon; Scheme-I cannot. The consistence in diurnal variations between cloud water path used for radiation calculation (Fig. 11e) and prognostic cloud water 
(Fig. 11f) can also be simulated by Scheme-III. Figure 12 shows the diurnal cycles of predicted cloud water and cloud water for radiation calculation at the pressure level $\sim 900 \mathrm{hPa}$, illustrating that prognostic cloud water content in all experiments reaches a minimum value around noontime. Similarly, the consistence between diurnal variation of cloud water path for radiation calculation (Figs. 12a, c) and cloud water (Figs. 12b, d) only exists in the experiments using Scheme-II and Scheme-III, while Scheme-I shows the opposite variation, reaching its maximum during daytime and minimum during nighttime.

(a) T.5 Qc $(\mathrm{mg} / \mathrm{kg})$

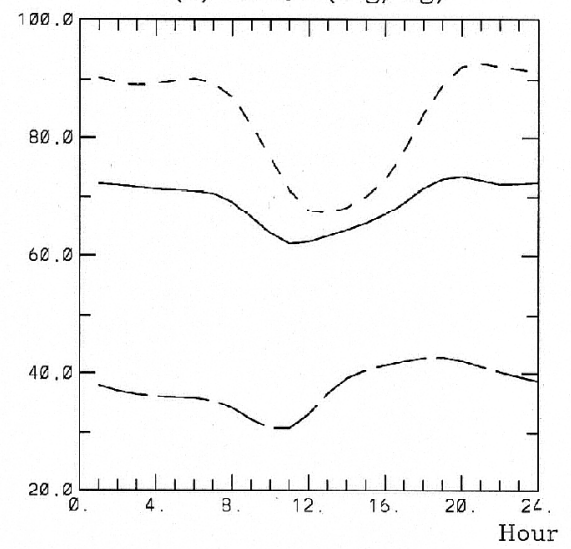

(c) L5 QC

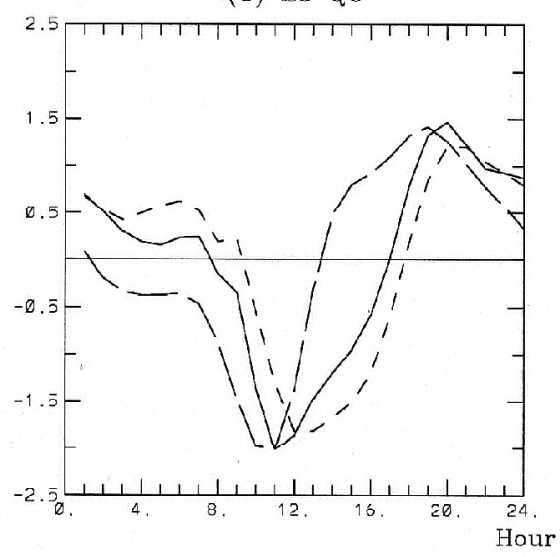

(b) L5 Clwp $\left(\mathrm{g} / \mathrm{m}^{2}\right)$

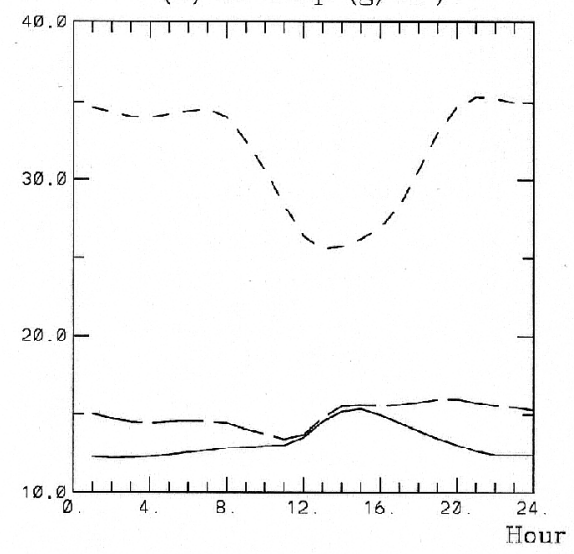

(d) L5 Clwp

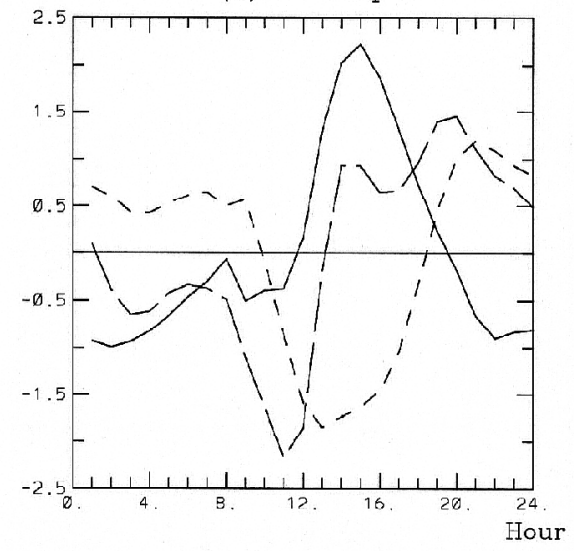

Fig. 12. The simulated regional and seasonal averaged diurnal cycles at fifth sigma level ( $\sim 900 \mathrm{hPa})$. Shows (a) the cloud water mixing ratio; (b), the cloud water path for the radiation calculation; (c), the normalized liquid water mixing ratio; and (d), the normalized cloud water path for the radiation calculation. Solid, dashed, and broken lines indicate the results of EX_diag, EX_prog, and EX_hyb, respectively. 


\section{CONCLUSIONS}

We used SUNYA RCM to evaluate three cloud schemes (for both cloud cover and cloud water) in simulating CRF, the associated cloud structure, and the surface climate during the 1991 EASM, a year featuring extensive cloud cover and heavy monsoon rains over the YangtzHuai River valley in Eastern China. The first two schemes, categorized as diagnostic and prognostic clouds, are the schemes commonly used in RCMs, while the third is a hybrid scheme. All three schemes simulate larger summer mean CRF net cooling and weaker seasonal variation of shortwave CRF, due mainly to the small seasonal variation of low-level cloud cover and water. The hybrid scheme, because of its consideration of sub-grid scale cloud variability, yields the least biases and results in a better surface temperature simulation. The improvement mainly comes from a decrease in shortwave CRF biases during precipitation inactive periods (June 21st to 29th and after July 14th). A smaller autoconversion threshold and consideration of fractional clouds in the hybrid scheme effectively reduce mean cloud water and shortwave CRF biases. Nevertheless, in June and July, shortwave CRF is still large due to the presence of optically thick low-level clouds, as a result of a very moist lower troposphere which is also closely related to other model physical processes, such as cumulus parameterization and land surface processes.

The analyses of surface heat budget indicate that responses of latent and sensible heat fluxes provide a strong negative feedback to reduce the differences in surface climate caused by the differences in CRF. Through turbulence mixing processes, reduced surface heat fluxes affect the thermodynamic fields and cloud fields of the lower troposphere for further cloudradiative-climate interaction. According to diurnal variations of variables in the low troposphere, it is found that the diagnostic scheme results in inconsistency between clouds decided by microphysics and clouds used in the radiation model, leading to thicker cloud optical depth in the afternoon lowering the surface maximum temperatures.

Acknowledgements This research was supported by Biological and Environmental Research, Office of Science, U.S. Department of Energy. The work represents a portion of Chao-Tzuen Cheng's doctoral dissertation at the State University of New York at Albany.

\section{REFERENCES}

Bishop, J. K. B., W. B. Rossow, and E. G. Dutton 1997: Surface solar irradiance from the International Satellite Cloud Climate Project 19983-1991.J. Geophys. Res., 102, 68836910.

Cheng, C. T., 2003: A regional climate model study of cloud radiative forcing and its role in the 1991 East Asian summer monsoon. Ph.D. dissertation, Dept. Atmos. Sci., Univ. at Albany, SUNY, $154 \mathrm{pp}$.

Collins, W. D., F. P. J. Valero, P. J. Flatau, D. Lubin, H. Grassl, and P. Pilewskie, 1996: Radiative effects of convection in the tropical Pacific. J. Geophys. Res, 101, 1499915012. 
Del Genio, A. D., M. S. Yao, W. Kovari, and L. W. Lo., 1996: A prognostic cloud water parameterization for global climate models. J. Climate, 9, 270-304.

Dudek, M. P., X. Z. Liang, and W. C. Wang, 1996: A regional climate model study of the scale dependence of cloud-radiation interactions. J. Climate, 9, 1221-1234.

Dudhia, J., 1989: Numerical study of convection observed during the winter monsoon experiment using a mesoscale two-dimension model.J. Atmos. Sci., 46, 3077-3107.

Fowler, L., D. A. Randall, and S. A. Rutledge, 1996: Liquid and ice cloud microphysics in the CSU general circulation model. Part I: Model description and simulated microphysical processes. J. Climate, 9, 489-529.

Giorgi, F., Y. Huang, K. Nishizawa, and C. Fu, 1999: A seasonal cycle simulation over eastern Asia and its sensitivity to radiative transfer and surface processes.J. Geophys. Res., 104, 6403-6423.

Gong, W., and W.-C. Wang, 2000: A regional model simulation of the 1991 severe precipitation event over Yangtze-Huai river valley. Part II: Model bias. J. Climate, 13, 93-108.

Grell, A. G., 1993: Prognostic evaluation of assumptions used by cumulus parameterizations. Mon. Wea. Rev., 121, 7764-7787.

Grell, A. G., J. Dudhia, and D. R. Stauffer, 1994: A description of the fifth-generation Penn State/NCAR mesoscale model (MM5). NCAR Tech. Note NCAR/TN398+STR, National Center for Atmos. Res., Boulder, CO, 117 pp.

Gultepe, I., G. A. Isaac, W. R. Leaitch, and C. M. Banic, 1996: Parameterizations of marine stratus microphysics based on insitu observations: Implications for GCMs.J. Climate, 9, 345-357.

Hack, J. J., 1998: Sensitivity of the simulated climate to diagnostic formulation for cloud liquid water. J. Climate, 11, 1497-1515.

Harrison, E.F., P. Minnis, B. R. Barkstorm, V. Ramanathan, R. D. Cess, and G. G. Gibson, 1990: Seasonal variation of cloud radiative forcing derived from the earth radiation budget experiment. J. Geophys. Res., 95, 18687-18703.

Hartmann, D. L., L. A. Moy, and Q. Fu, 2001: Tropical convection and the energy balance at the top of the atmosphere. J. Climate, 14, 4495-4511.

Heymsfield, A. J., and L. J. Donner, 1990: A scheme for parameterizing ice-cloud water content in general circulation models. J. Atmos. Sci., 47, 1865-1877.

Hooker, S. B., and W. E. Easia, 1993: An overview of the SeaWiFS project.Eos Trans. AGU, 74, 245-246.

Iacobellis, S. F., and C. J. Somerville, 2000: Implications of microphysics for cloud-radiation parameterizations: Lessons from TOGA COARE. J. Atmos. Sci., 57, 161-183.

IPCC, 2001: Intergovernmental Panel on Climate Change, Climate Change 2001, The Scientific Basis, In: Houghton J. T., Y. Ding, D. J. Griggs, M. Noguer, P. J. van der Linden and D. Xiaosu, (Eds.), Cambridge Univ. Press, UK, 94 pp.

Kiehl, J. T., 1994a: Sensitivity of a GCM climate simulation to differences in continental versus maritime cloud drop size. J. Geophys. Res., 99, 23107-23115.

Kiehl, J. T., 1994b: On the observed near cancellation between Longwave and shortwave cloud forcing in tropical regions. J. Climate, 7, 559-565 
Kiehl, J. T., J. J. Hack, G. B. Bonan, B. A. Boville, D. L. Williamson, and P. J. Rasch, 1998: The national center for atmospheric research community climate model: CCM3.J. Climate, 11, 1131-1149.

Liang, X. Z., and W. C. Wang, 1995: A GCM study of the climatic effect of 1979-1992 Ozone trend. Atmospheric Ozone as a Climate Gas, In: Wang, W. C., and I. S. A. Isaksen, (Eds.), NATO ASI Series, 32, Springer-Veriag, 259-288.

Lin, Y. L., R. D. Farley, and H. D. Orville, 1983: Bulk parameterization of the snow field in a cloud model. J. Climate Appl. Meteor., 22, 1065-1092.

Leung, L. R., S. J. Ghan, Z. C. Zhao, Y. Luo, W. C. Wang, and H. Wei, 1999: Intercomparison of regional climate simulations of the 1991 summer monsoon in east Asia: Special issue on "New Development and Applications in regional climate models." J. Geophys. Res., 104, 6425-6454.

Lohmann, U., J. Feichter, C. C. Chuang, and J. E. Penner, 1999: Prediction of the number of cloud droplets in the ECHAM GCM. J. Geophys. Res., 104, 9169-9198.

Lohmann, U., and E. Roeckner, 1996: Design and performance of a new cloud microphysics scheme developed for the ECHAM general circulation model. Clim. Dyn., 12, 557-572.

Lu, E., Y. Ding, M. Murakami, and K. Takaashi 1998: Nature of precipitation and activity of cumulus convection during the $1991 \mathrm{Mei}-\mathrm{Yu}$ season of Changjiang-Huaihe river basin. Acta Meteor. Sinica, 12, 75-91.

Martin, G. M., A. W. Johnson, and A. Spice, 1994: The measurement and parameterization of effective radius of droplets in warm stratocumulus clouds. J. Atmos. Sci., 51, 18231842.

Pruppacher, H. R., and J. D. Klett, 1997. Microphysics of clouds and Precipitation. Kluwer Acad. Publ., Dordrecht/Boston/London, 954 pp.

Rajeevan, M., and J. Srinivasan, 2000: Net cloud radiative forcing at the top of the atmosphere in the Asian Monsoon region. J. Climate, 13, 650-657.

Randall, D. A., M. Khairoutdinov, A. Arakawa, and W. Grabowski, 2003: Breaking the Cloud Parameterization Deadlock. Bull. Am. Meteor. Soc., 84, 1547-1564.

Ramanathan, V., 1987: The role of earth radiation budget studies in climate and general circulation research. J. Geophys. Res., 92, 4075-4095.

Rasch, P. J., and J. E. Kristjánsson, 1998: A comparison of the CCM3 model climate using diagnosed and predicted condensate parameterizations. J. Climate, 11, 1587-1914.

Reid, J. S., P. V. Hobbs, A. L. Rangno, and D. A. Hegg, 1999: Relationships between cloud droplet effective radius, liquid water content and droplet concentration for warm clouds in Brazil embedded in biomass smoke. J. Geophys. Res., 104, 6145-6153.

Rossow, W. B., and R. A. Schiffer, 1999: Advances in Understanding Clouds from ISCCP. Bull. Am. Meteor. Soc., 80, 2261-2287.

Rutledge, S. A., and P. V. Hobbs, 1983: The mesoscale and microscale structure and organization of clouds and precipitation in midlatitude cyclones. Part VIII: A model for the "seeder-feeder" processes in warm-frontal rainbands. J. Atmos. Sci., 40, 1185-1206.

Sharma, O. P., H. L. Treut, G. Seze, L. Fairhead, and R. Sadourny, 1998: Interannual variations of summer monsoons: Sensitivity to cloud radiative forcing.J. Climate, 11, 18831905. 
Slingo, A., and J. M. Slingo, 1991: Response of the national center for atmospheric research community climate model to improvements in the representation of clouds.J. Geophys. Res., 96, 15341-15357.

Tao, S., and L. Chen, 1987: A review of recent research on the East Asian summer monsoon in China. Monsoon Meteorology, In: Chang, C. P., and T. N. Krishnamurti, (Eds.), Oxford Univ. Press, 10-92.

Tian, B., and V. Ramanathan, 2002: Role of tropical clouds in surface and atmospheric energy budget. J. Climate, 15, 296-305.

Tiedtke, M., 1993: Representation of clouds in large-scale models. Mon, Wea. Rev., 121, 3040-3061.

Wang, W. C., W. Gong, and H. Wei, 2000: A regional model simulation of the 1991 severe precipitation event over Yangtze-Huai river valley. Part I: Precipitation and circulation statistics. J. Climate, 13, 74-92.

Xue, Y., M. J. Fennessy, and P. J. Sellers., 1996: Impact of vegetation properties on U. S. summer weather prediction. J. Geophys. Res., 101, 7419-7430. 